\title{
Factors controlling the groundwater transport of U, Th, Ra, and Rn
}

\author{
A Tricca, D Porcelli and G J WAsserburg \\ The Lunatic Asylum of the Charles Arms Laboratory, Division of Geological and Planetary Sciences, \\ California Institute of Technology, Pasadena, CA 91125 USA \\ email: tricca@gps.caltech.edu
}

A model for the groundwater transport of naturally occurring $\mathrm{U}$, Th, Ra, and Rn nuclides in the ${ }^{238} \mathrm{U}$ and ${ }^{232} \mathrm{Th}$ decay series is discussed. The model developed here takes into account transport by advection and the physico-chemical processes of weathering, decay, $\alpha$-recoil, and sorption at the water-rock interface. It describes the evolution along a flowline of the activities of the ${ }^{238} \mathrm{U}$ and ${ }^{232} \mathrm{Th}$ decay series nuclides in groundwater. Simple sets of relationships governing the activities of the various species in solution are derived, and these can be used both to calculate effective retardation factors and to interpret groundwater data. For the activities of each nuclide, a general solution to the transport equation has been obtained, which shows that the activities reach a constant value after a distance $\bar{x}_{i}$, characteristic of each nuclide. Where $\bar{x}_{i}$ is much longer than the aquifer length, (for ${ }^{238} \mathrm{U},{ }^{234} \mathrm{U}$, and ${ }^{232} \mathrm{Th}$ ), the activities grow linearly with distance. Where $\bar{x}_{i}$ is short compared to the aquifer length, (for ${ }^{234} \mathrm{Th},{ }^{230} \mathrm{Th},{ }^{228} \mathrm{Th},{ }^{228} \mathrm{Ra}$, and ${ }^{224} \mathrm{Ra}$ ), the activities rapidly reach a constant or quasi-constant activity value. For ${ }^{226} \mathrm{Ra}$ and ${ }^{222} \mathrm{Rn}$, the limiting activity is reached after $1 \mathrm{~km}$.

High $\delta^{234} \mathrm{U}$ values (proportional to the ratio $\varepsilon^{234} \mathrm{Th} / \mathrm{w}_{238} \mathrm{U}$ ) can be obtained through high recoil fraction and/or low weathering rates. The activity ratios ${ }^{230} \mathrm{Th} /{ }^{232} \mathrm{Th},{ }^{228} \mathrm{Ra} /{ }^{226} \mathrm{Ra}$ and ${ }^{224} \mathrm{Ra} /{ }^{226} \mathrm{Ra}$ have been considered in the cases where either weathering or recoil is the predominant process of input from the mineral grain. Typical values for weathering rates and recoil fractions for a sandy aquifer indicate that recoil is the dominant process for Th isotopic ratios in the water. Measured data for Ra isotope activity ratios indicate that recoil is the process generally controlling the Ra isotopic composition in water. Higher isotopic ratios can be explained by different desorption kinetics of Ra. However, the model does not provide an explanation for ${ }^{228} \mathrm{Ra} /{ }^{226} \mathrm{Ra}$ and ${ }^{224} \mathrm{Ra} /{ }^{226} \mathrm{Ra}$ activity ratios less than unity.

From the model, the highest ${ }^{222} \mathrm{Rn}$ emanation equals $2 \varepsilon$. This is in agreement with the hypothesis that ${ }^{222} \mathrm{Rn}$ activity can be used as a first approximation for input by recoil (Krishnaswami et al 1982). However, high ${ }^{222} \mathrm{Rn}$ emanation cannot be explained by production from the surface layer as formulated in the model. Other possibilities involve models including surface precipitation, where the surface layer is not in steady-state.

\section{Introduction}

Numerous studies have been conducted on the groundwater transport of trace elements in order to predict the impact of anthropogenic contaminants (e.g. Allen et al 1993; Zheng and Bennett 1995). Naturally occurring U, Th, and Ra isotopes can serve as analogues for radioactive pollutants (e.g. Ivanovich et al 1992; Dozol et al 1993). These isotopes have a wide range of half-lives, and their inter-relationships in the ${ }^{238} \mathrm{U}$ and ${ }^{232} \mathrm{Th}$ decay series can be used to constrain groundwater supply and removal rates over different time-scales. Examples of pronounced $\mathrm{U}$ series disequilibrium have been found in groundwaters, clearly showing that in open systems such as natural aquifers, water-rock interactions can induce

Keywords. Groundwater; trace elements; isotopes; pollutants. 
significant elemental and isotopic fractionations (see e.g. Hubbard et al 1984; Andrews et al 1989, Banner et al 1990; Osmond and Cowart 1992; Bonotto and Andrews 1993). Although the thermodynamic properties of actinides and their daughter products are reasonably well known (see Langmuir 1997), data acquired under simple and well-constrained laboratory conditions are difficult to apply to more complex natural systems (e.g. Coles and Ramspott 1982), and interpretations of field data using theoretical models of $\mathrm{U} / \mathrm{Th}$ series nuclide groundwater transport are limited (see review by Ku et al 1992). Andrews et al (1982, 1989) considered physico-chemical mechanisms for radionuclide supply and removal, but not advective transport, and calculated the time-scale of waterrock interaction. In an important contribution, Krishnaswami et al (1982) calculated sorption reaction rate constants and residence times of daughter nuclides by deducing recoil inputs from ${ }^{222} \mathrm{Rn}$ activities, although without considering the effects of dissolution, precipitation or advective transport. Davidson and Dickson (1986) included dispersive flow in a model of the transport of $\mathrm{U}$ and $\mathrm{Ra}$ isotopes, but did not consider dissolution and precipitation.

A model for the combined groundwater transport of naturally occurring $\mathrm{U}, \mathrm{Th}, \mathrm{Ra}$, and Rn nuclides in the ${ }^{238} \mathrm{U}$ and ${ }^{232} \mathrm{Th}$ decay series is discussed here that takes into account transport by advection as well as the physico-chemical processes of weathering, decay, $\alpha$-recoil, and sorption at the water-rock interface. General transport equations for the nuclides are used to obtain analytical solutions for groundwater concentrations along a flowline. Simple sets of relationships governing the activities of the various species in solution are derived, and these can be used both to calculate effective retardation factors and to interpret groundwater data. Comparison of the model and aquifer data provide quantitative values for geochemical parameters in a natural aquifer such as weathering rates, distribution constants between the solid and the aqueous phases, and sorption kinetics. The model can also be used as a benchmark for determining whether the distributions of naturally occurring nuclides are consistent with the simple retardation models for point-source anthropogenic nuclides that are typically employed. A complete discussion of the model will be provided elsewhere as well as application of the model to interpreting data from an unconfined sandy aquifer (Tricca, Porcelli, Baskaran, and Wasserburg, submitted).

\section{Radionuclide groundwater transport model}

\subsection{Model development}

The one-dimensional groundwater model discussed here considers three phases: groundwater with a con- stant linear velocity $v$; the rock comprised of large grains typical of the aquifer mineralogy and of small minor phases enriched in radioactive elements; and a surface layer that coats some fraction of the grains and where physico-chemical reactions take place (figure 1). The rock has a porosity $n$. The surface layer is characterized by a specific surface area $S$ (area per unit volume of rock) and has a thickness $\xi$. All parameters used in the model are listed in table 1 . The model aquifer is in steady state; i.e., the concentrations of species in solution, in the rock, and in the surface layer do not vary with time at any given location. Flow through an aquifer that has changes in physical parameters can be simply solved for the steady state case by using the values from one segment as the initial boundary conditions for the next segment.

The model considers transport of radionuclides by advection along a flowline; diffusive transport and hydrodynamic dispersion are not considered. The distance along the flowline is $x$, where $x=0$ at the water table. The supply of each radionuclide to the groundwater occurs by weathering from primary phases with a nuclide-specific weathering rate $w_{i}$, desorption from the surface layer, and recoil from decay of parent nuclides within both aquifer mineral grains and the surface coating. Removal from solution occurs by adsorption onto the active surface layer and decay in the dissolved phase.

In the present discussion, it is assumed that $\mathrm{U}$ in the groundwater does not react with the surface layer. This is consistent with various field studies that have concluded that $\mathrm{U}$ in oxic groundwaters can exhibit generally conservative behavior (e.g. Hodge et al 1996). In contrast, Th and Ra are assumed to be highly surface-reactive. Rn, a noble gas, is not surfacereactive. Given the typically low activities of the radionuclides in natural ground waters relative to those in the solids, the production by parent decay in solution of any long-lived radionuclide is negligible compared to that supplied to the water by parent decay in the rock or in the surface layer. The steady state general transport equation for any nuclide $i$ in the dissolved phase is:

$$
\begin{aligned}
\frac{\mathrm{d}^{i} c_{w}}{\mathrm{~d} x}= & \frac{\rho_{r} \cdot(1-n)}{\rho_{w} \cdot n \cdot v} \cdot\left(w_{i} \cdot{ }^{i} c_{r}+\varepsilon_{i} \cdot \lambda_{p} \cdot{ }^{p} c_{r}+{ }^{i} \hat{k}_{-1}\right. \\
& \left.\cdot \frac{\rho_{s c} \cdot S}{\rho_{r}} \cdot{ }^{i} c_{s c}+f_{i} \cdot \frac{\rho_{s c} \cdot S \cdot \xi}{\rho_{r}} \cdot \lambda_{p} \cdot{ }^{p} c_{s c}\right) \\
& +\frac{\lambda_{p}}{v} \cdot{ }^{p} c_{w}-\left(\frac{\lambda_{i}}{v}+{ }^{i} \hat{k}_{i} \cdot \frac{S \cdot(1-n)}{v \cdot n}\right) \cdot{ }^{i} c_{w}
\end{aligned}
$$

where $\rho_{r}, \rho_{w}$ and $\rho_{s c}$ are the densities of the rock, water, and surface layer, respectively, and ${ }^{i} c_{w},{ }^{i} c_{r}$, and ${ }^{i} c_{s c}$ are the concentrations of $i$ in these respective phases. The parameter $\varepsilon_{i}$ is the fraction of nuclide $i$ produced by $\alpha$-decay in the rock and released into the water by recoil. For simple geometries, $\varepsilon_{i}$ is directly 


\section{Phases}

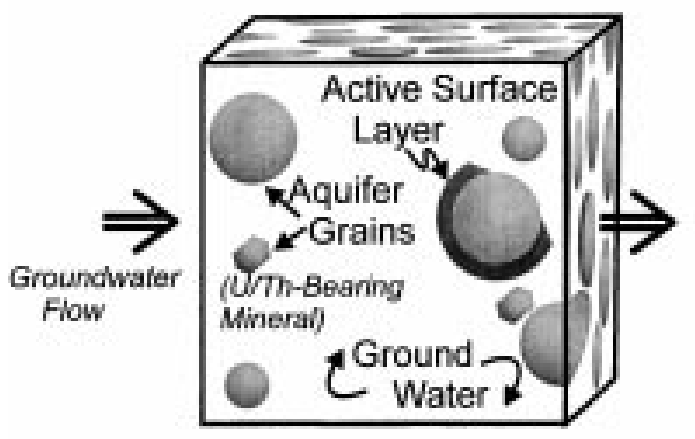

Groundwater
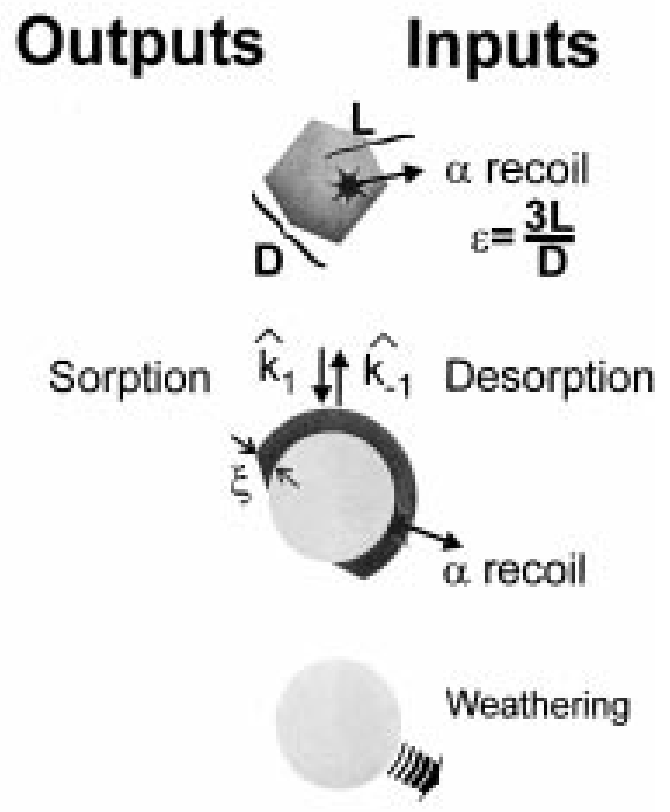

Decay $P * i \quad \begin{gathered}\text { Parent } \\ \text { Decay }\end{gathered}$

Figure 1. Model of an aquifer with the three phases and fluxes considered.

Table 1. Model parameters.

\begin{tabular}{|c|c|c|c|}
\hline Symbol & Parameter & Units & Value $^{1}$ \\
\hline$n$ & porosity & - & 0.3 \\
\hline$\rho_{r}$ & rock density & $\mathrm{g} / \mathrm{cm}^{3}$ & 2.7 \\
\hline$\rho_{w}$ & water density & $\mathrm{g} / \mathrm{cm}^{3}$ & 1 \\
\hline$\rho_{s c}$ & surface coating density & $\mathrm{g} / \mathrm{cm}^{3}$ & 2.7 \\
\hline$v$ & average linear water flow velocity & $\mathrm{cm} / \mathrm{sec}$ & $(2-7) \times 10^{-4}$ \\
\hline${ }^{i} c_{w}$ & concentration of the nuclide $i$ in solution & $\mathrm{mol} / \mathrm{kg}$ of water & \\
\hline${ }^{i} c_{s c}$ & concentration of $i$ in the surface layer & $\mathrm{mol} / \mathrm{kg}$ of surface layer & \\
\hline${ }^{i} c_{r}$ & concentration of $i$ in the rock & $\mathrm{mol} / \mathrm{kg}$ of rock & \\
\hline$r$ & average grain radius & $\mathrm{m}$ & $(10-100) \times 10^{-6}$ \\
\hline$L_{i}$ & $\alpha$-recoil length of the nuclide $i$ & $\mathrm{~m}$ & $2 \times 10^{-8}$ \\
\hline$\xi$ & surface coating thickness & $\mathrm{m}$ & $10^{-6}$ \\
\hline$S$ & specific surface area per volume of rock & $\mathrm{cm}^{-1}$ & \\
\hline$w_{i}$ & weathering rate & $\sec ^{-1}$ & \\
\hline$\varepsilon_{i}$ & recoil fraction of the nuclide $i$ & & $(0.6-6) \times 10^{-5}$ \\
\hline$R_{\text {eman }}$ & emanation fraction of $\mathrm{Rn}$ & & \\
\hline$\lambda_{i}$ & decay rate of nuclide $i$ & $\sec ^{-1}$ & \\
\hline$i \hat{k}_{-1}$ & $\begin{array}{l}\text { velocity of the nuclide } i \text { desorbing from the } \\
\text { surface layer into the liquid phase }\end{array}$ & $\mathrm{cm} \cdot \mathrm{sec}^{-1}$ & \\
\hline${ }^{i} \hat{k}_{1}$ & velocity of nuclide $i$ adsorbing onto the surface layer & $\mathrm{cm}_{\mathrm{sec}}{ }^{-1}$ & \\
\hline$f_{p}$ & $\begin{array}{l}\text { fraction of nuclide } i \text { released in the water } \\
\text { by decay of its sorbed parent } p\end{array}$ & & 0.5 \\
\hline$F_{p}$ & $\begin{array}{l}\text { fraction of nuclide } i \text { released in the water by } \\
\text { desorption of } i \text { and decay of its sorbed parent }\end{array}$ & & 0.5 \\
\hline${ }^{i} D$ & $\begin{array}{l}\text { Distribution coefficient of nuclide } i \text { between the } \\
\text { surface coating and the groundwater }\end{array}$ & & \\
\hline$\chi_{i}$ & $\begin{array}{l}\text { Ratio of the number of atoms } i \text { in the surface } \\
\text { coating to the number of atoms of } i \text { in solution }\end{array}$ & & See table 2 \\
\hline $\bar{x}_{i}$ & Characteristic length scale of $i$ & & See table 2 \\
\hline
\end{tabular}

\footnotetext{
${ }^{1}$ Typical values for the Upper Glacial aquifer in Long Island, New York.
} 
Table $2 . \quad \bar{x}_{i}$ values for the different radionuclides in the Long Island aquifer.

\begin{tabular}{|c|c|c|c|c|c|}
\hline Radionuclide & Half life & $\begin{array}{c}\lambda_{i} \\
\sec ^{-1}\end{array}$ & $\chi_{i}$ & $\begin{array}{c}\bar{x}_{i \max }\left(\chi_{i=0}\right) \\
\text { meters }\end{array}$ & $\begin{array}{c}\bar{x}_{i} \\
\text { meters }\end{array}$ \\
\hline${ }^{238} \mathrm{U}$ & $4.47 \times 10^{9} \mathrm{y}$ & $4.29 \times 10^{-18}$ & 0 & $4.07 \times 10^{11}$ & $4.07 \times 10^{11}$ \\
\hline${ }^{234} \mathrm{Th}$ & $24.1 \mathrm{~d}$ & $3.33 \times 10^{-7}$ & 700 & 6.01 & $1 \times 10^{-2}$ \\
\hline${ }^{234} \mathrm{U}$ & $2.46 \times 10^{5} \mathrm{y}$ & $8.93 \times 10^{-14}$ & 0 & $2.24 \times 10^{7}$ & $2 \times 10^{7}$ \\
\hline${ }^{230} \mathrm{Th}$ & $7.54 \times 10^{4} y$ & $2.92 \times 10^{-13}$ & $2 \times 10^{6}$ & $6.86 \times 10^{6}$ & 3 \\
\hline${ }^{226} \mathrm{Ra}$ & $1599 \mathrm{y}$ & $1.37 \times 10^{-11}$ & 700 & $1.46 \times 10^{5}$ & $3 \times 10^{2}$ \\
\hline${ }^{222} \mathrm{Rn}$ & $3.82 \mathrm{~d}$ & $2.10 \times 10^{-6}$ & 0 & $9.54 \times 10^{-1}$ & $9 \times 10^{-1}$ \\
\hline${ }^{232} \mathrm{Th}$ & $1.4 \times 10^{10} \mathrm{y}$ & $1.57 \times 10^{-18}$ & $2 \times 10^{6}$ & $1.27 \times 10^{12}$ & $6 \times 10^{5}$ \\
\hline${ }^{228} \mathrm{Ra}$ & $5.76 \mathrm{y}$ & $3.82 \times 10^{-9}$ & 100 & $5.24 \times 10^{2}$ & 5 \\
\hline${ }^{228} \mathrm{Th}$ & $1.913 \mathrm{y}$ & $2 \times 10^{4}$ & 1000 & $1.74 \times 10^{2}$ & $9 \times 10^{-3}$ \\
\hline${ }^{224} \mathrm{Ra}$ & $3.6 \mathrm{~d}$ & $2.23 \times 10^{-6}$ & 0.2 & $8.97 \times 10^{-1}$ & 0.9 \\
\hline${ }^{220} \mathrm{Rn}$ & $55 \mathrm{sec}$ & $1.26 \times 10^{-2}$ & 0 & $1.59 \times 10^{-4}$ & $1.59 \times 10^{-4}$ \\
\hline
\end{tabular}

related to the radius $r$ of the emitting mineral and to the specific recoil length $L$ of the nuclide by $\varepsilon_{i} \cong 3 L / 2 r$ when $L \ll r$ (Kigoshi 1971). For the nuclides of interest here, $\mathrm{L} \sim 200 \AA$ (Fleischer 1982). Note that U-Th bearing accessory mineral grains are often much smaller than the major aquifer mineral grains. For UTh bearing grains in the size range of $10-100 \mu \mathrm{m}$, the range of $\varepsilon$ is $6 \times 10^{-3}$ to $6 \times 10^{-4}$. The fraction of daughter atoms $i$ produced by decay of the parent nuclides that are adsorbed at the surface layer and released into solution is $f_{i}$. For $\alpha$-decay, $f_{i}$ is dependent on the thickness $\xi$ of the surface layer, with a maximum value of 0.5 when $\xi \ll L$. For low-energy $\beta$-decay, $f_{i}$ is either 1 if the daughter $i$ is not adsorbed and so completely released into solution, or 0 if it is strongly adsorbed. Sorption is characterized by the parameter $\hat{k}_{1}$, the average velocity with which atoms $i$ in solution impact and sorb onto the surface layer. $\hat{k}_{-1}$ is the velocity of atoms $i$ in the surface layer that cross the surface-water boundary to go into solution. Sorption kinetics are assumed to follow a first-order rate law.

Assuming that the surface layer is in steady state (i.e. $\left.\mathrm{d}^{i} c_{s c} / \mathrm{d} t=0\right)$, then:

$$
\begin{gathered}
{ }^{i} c_{s c}={ }^{i} D \cdot\left(\frac{\rho_{w}}{\rho_{s c}}\right) \cdot{ }^{i} c_{w}+\left(1-\theta \cdot f_{i}\right) \\
\cdot\left(\frac{\xi}{\hat{i}_{-1}+\lambda_{i} \cdot \xi}\right) \cdot \lambda_{p} \cdot{ }^{p} c_{s c}
\end{gathered}
$$

where

$$
{ }^{i} D=\frac{{ }^{i} \hat{k}_{1}}{\left({ }^{i} \hat{k}_{-1}+\lambda_{i} \cdot \xi\right)} .
$$

In the case of $\alpha$-decay, $\theta=2$, while for $\beta$-decay, $\theta=1$. Note that combining equations (1) and (2) gives a linear differential equation for ${ }^{i} c_{w}$ with a characteristic exponential solution of the form $\exp \left(-x / \bar{x}_{i}\right)$, where

$$
\bar{x}_{i} \equiv \frac{v}{\lambda_{i} \cdot\left(1+\chi_{i}\right)}
$$

and

$$
\chi_{i} \equiv{ }^{i} D \cdot S \cdot \xi \cdot \frac{(1-n)}{n} .
$$

The parameter $\bar{x}_{i}$ is the length scale for transport and determines the distance required so that $\mathrm{d}^{i} c_{w} / \mathrm{d} x \approx 0$. Values of $\bar{x}_{i}$, calculated for a typical sandy aquifer, are listed in table 2 and will be used in the discussion. Radionuclide groundwater concentrations as a function of distance are obtained by sequentially solving equations (1) and (2) for each nuclide along the ${ }^{238} \mathrm{U}$ and ${ }^{232} \mathrm{Th}$ decay series. Note that if the solution is saturated in a species, the above treatment is not appropriate. In the case that the solution is saturated (or supersaturated), the "surface" layer concentration grows and is not in steady state. The steady state treatment presented here does not include the complexities involved with a growing adsorptive layer.

\section{Discussion}

The exact solutions to equations (1) and (2) are given for all nuclides in Appendix I. The equations for the asymptotic values for $x \rightarrow \infty$ are in Appendix II. Note that the concentrations are expressed in activities, where ${ }^{i} A={ }^{i} c \lambda_{i}$. For the purposes of discussion, typical values for the characteristics of a sandy aquifer will be used below for parameters of the model (see table 1). In the following sections, we consider the evolution along a flowline of the activity of some relevant nuclides from the ${ }^{238} \mathrm{U}$ and ${ }^{232} \mathrm{Th}$ decay series in groundwater. We then discuss the different general evolutions with distance of the activities in the groundwater, and the relevance of the initial input for the activities along the flowline. This is followed by consideration of the $\mathrm{Th}$ and $\mathrm{Ra}$ isotopic ratios in the water in case of predominant weathering or recoil. The last point focuses on the model predictions for ${ }^{222} \mathrm{Rn}$ activities in the water and their compatibility with measured high values in natural aquifers. 


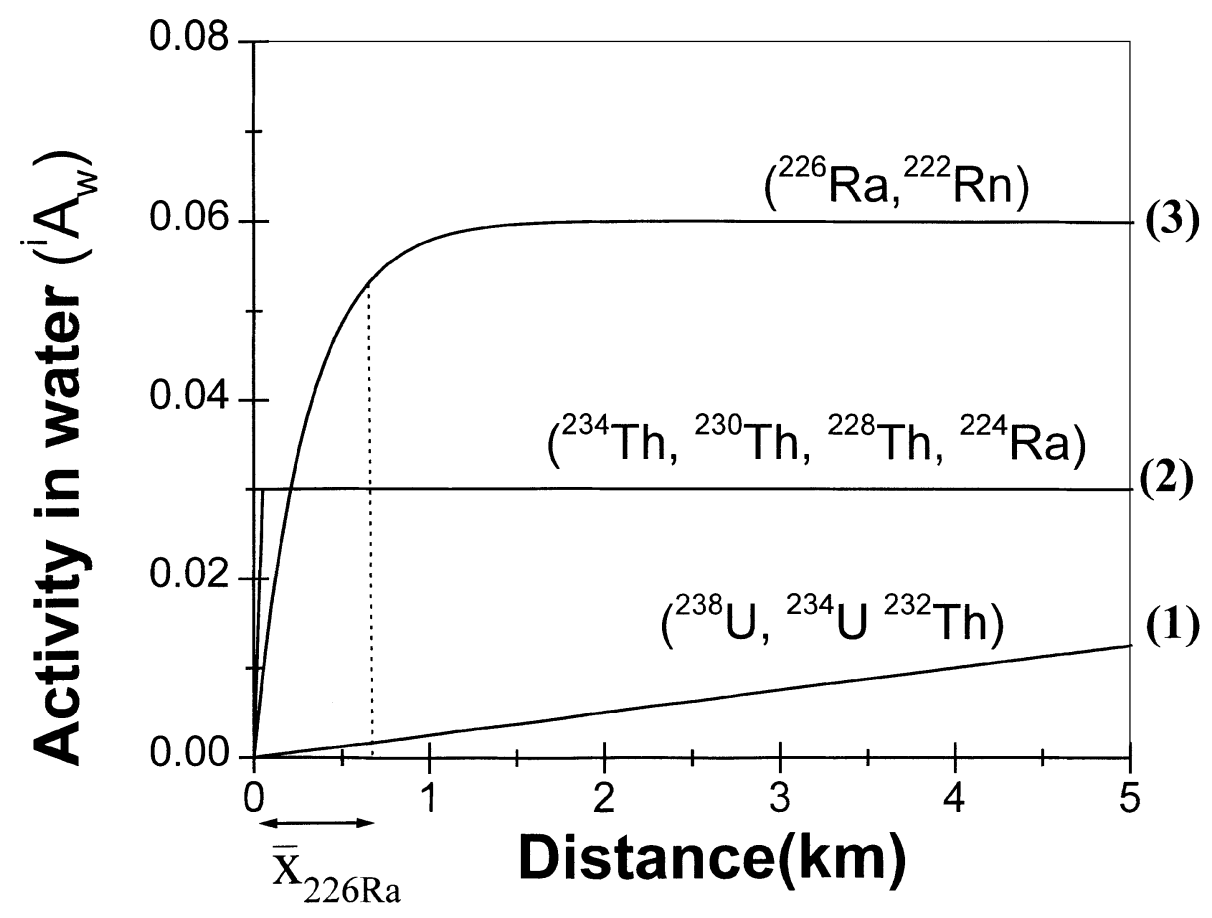

Figure 2. Nuclide activities in solution as a function of distance for different $\bar{x}_{i}$ values and arbitrary values for ${ }^{i} A_{w}$. Curve $(\mathbf{1})$ : the value of $\bar{x}_{i}$ is long compared to the length of the aquifer and ${ }^{i} A_{w}$ grows linearly with distance; curve $(\mathbf{2}): \bar{x}_{i}$ is short compared to the aquifer length: ${ }^{i} A_{w}$ reaches rapidly a constant value; curve $(\mathbf{3}): \bar{x}_{i}$ is intermediate ${ }^{i} A_{w}$ reaches a constant value after a characteristic distance. Values of $\bar{x}_{i}$ have been calculated using data from a typical sandy aquifer.

\subsection{The Behavior of long-lived ${ }^{238} U$ and ${ }^{232}$ Th}

For the very long-lived nuclides ${ }^{232} \mathrm{Th}$ and ${ }^{238} \mathrm{U}$, the $\bar{x}_{i}$ values $\bar{x}_{238 \mathrm{U}}=v / \lambda_{238 \mathrm{U}}$ and $\bar{x}_{232 \mathrm{Th}}=v / \lambda_{232 \mathrm{Th}}\left(1+\chi_{232 \mathrm{Th}}\right)$ are much larger than aquifer length scales; for instance, even assuming a high $\chi^{232} \mathrm{Th}$ value of $10^{6}$, $\bar{x}_{232} \mathrm{Th}$ remains of the order of $1000 \mathrm{~km}$ (see equation (4) and table 2). Consequently, for distances typically encountered in natural aquifers, the characteristic exponential of the general solutions given in Appendix I can be approximated by $\exp \left(-x / \bar{x}_{i}\right) \approx 1-x / \bar{x}_{i}$, so that ${ }^{232} \mathrm{Th}$ and the ${ }^{238} \mathrm{U}$ activities are

$$
\begin{aligned}
{ }^{i} A_{w} & ={ }^{i} A_{w \infty}\left(\frac{x}{\bar{x}_{i}}\right)+{ }^{i} A_{w 0} \\
& =\frac{\rho_{r}(1-n)}{\rho_{w} n}\left(\frac{w_{i} x}{v}\right){ }^{i} A_{r}+{ }^{i} A_{w 0}
\end{aligned}
$$

where ${ }^{i} A_{w \infty}$ is defined in Appendix II and ${ }^{i} A_{w 0}$ represents the activity of nuclide $i$ in the recharging water that meets the aquifer at the water table. Note that ${ }^{i} A_{w}$ increases linearly with distance along a flowline (figure 2) and is independent of $\chi_{i}$, the parameter that reflects the distribution of $i$ between the surface layer and the water. This is a direct result of the steady state treatment, so that the equation for the activity in the water is not dependent on the surface reactivity of nuclide $i$. For weathering rates of $3 \times 10^{-14} \mathrm{sec}^{-1}$ (corresponding to a rapid aquifer weathering time scale of $1 \mathrm{My}$ ) to $3 \times 10^{-16}$ $\sec ^{-1}$ (corresponding to a long weathering time scale of $100 \mathrm{My}),{ }^{238} \mathrm{U}$ activities of $(0.002-0.2) \mathrm{dpm} / \mathrm{kg}$ $\left((3-300) \times 10^{-9} \mathrm{~g} \mathrm{U} / \mathrm{kg}\right)$ are generated over $5 \mathrm{~km}$, respectively. Note that in general, the activities of $\mathrm{U}$ and Th are proportional to $w_{i} x / v$ so that, for a given distance, the determining parameter is $w_{i} / v$. Hence increasing the weathering rate or decreasing the groundwater velocity have equivalent effects upon ${ }^{i} A_{w}$. The ${ }^{232} \mathrm{Th} /{ }^{238} \mathrm{U}$ ratios in the groundwater are controlled by the relative supply rates of these nuclides by weathering; if ${ }^{232} \mathrm{Th} A_{w 0}={ }^{238} \mathrm{U} A_{w 0}=0$, then ${ }^{232} \mathrm{Th} A_{w}{ }^{238} \mathrm{U} A_{w}=w_{232} \mathrm{Th} / w_{238} \mathrm{U}\left({ }^{232} \mathrm{Th} A_{r} /{ }^{238} \mathrm{U} A_{r}\right)$. Typical values of both $\mathrm{Th}$ and $\mathrm{U}$ activities found in ground waters $\left({ }^{238} \mathrm{U} c_{w} \approx 4-20 \mathrm{ng} / \mathrm{kg}\right.$ and ${ }^{232} \mathrm{Th} c_{w} \approx 30-200 \mathrm{pg} /$ $\mathrm{kg}$ ) and a $\mathrm{Th} / \mathrm{U}$ activity ratio in the rock $\sim 1$, generally found in aquifers, therefore implies: $w_{232} \mathrm{Th} /$ $w_{238} \approx 10^{-2}$. Generalizing these results, it is seen that the weathering rate for Th is about 100 times smaller than that of $\mathrm{U}$.

\section{$3.2^{234} \mathrm{Th}$}

The nuclide ${ }^{234} \mathrm{Th}$ is distinctive in being a short-lived daughter nuclide produced by a non-reactive parent $\left({ }^{238} \mathrm{U}\right)$. Therefore, there are no inputs due to production within the surface layer. The activity of ${ }^{234} \mathrm{Th}$ in the water is given by

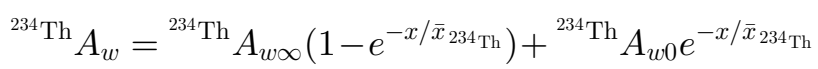


where

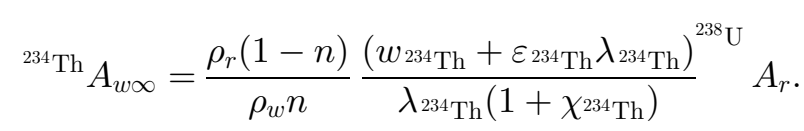

The very short half-life of ${ }^{234} \mathrm{Th}$ results in a value of $\bar{x}_{234} \mathrm{Th}$ that is small, and so the evolution along a flowline of ${ }^{234} \mathrm{Th}$ activity in groundwater is distinctive from that of the parent ${ }^{238} \mathrm{U}$. For a sandy aquifer, where $\chi_{234} \mathrm{Th}$ equals $10^{3}$ (table 2), $\bar{x}_{234} \mathrm{Th}=1 \mathrm{~cm}$ and the ${ }^{234} \mathrm{Th}$ activity reaches the asymptotic value ${ }^{234} \mathrm{Th} A_{w \infty}$ after a distance of only a few $\mathrm{cm}$ (figure 2). It follows that ${ }^{234} \mathrm{Th}$ is locally governed and the input from the vadose zone does not govern its behavior over significant distances. Note that, because ${ }^{238} \mathrm{U} A_{s c}=0$, ${ }^{234} \mathrm{Th} A_{s c}={ }^{234} \mathrm{Th} D\left(\rho_{w} / \rho_{s c}\right){ }^{234} \mathrm{Th} A_{w}$ (equation (2)). It can be seen that $\chi^{234} \mathrm{Th}$ is equal to the ratio of number of ${ }^{234} \mathrm{Th}$ atoms in the surface layer to that in the water (see equation (5)). The input process that dominantly controls the concentration of ${ }^{234} \mathrm{Th}$ in groundwater is determined by the relative magnitudes of $w_{234} \mathrm{Th}$ and $\varepsilon_{234}{ }^{\mathrm{Th}} \lambda^{234} \mathrm{Th}$ (equation (8)). Even for a rapid weathering rate of ${ }^{234} \mathrm{Th}$ of $w_{234} \mathrm{Th} \leq 10^{-14} \mathrm{sec}^{-1}, w_{234} \mathrm{Th}$ is very small compared to the expected $\lambda_{234} \mathrm{Th} \varepsilon^{234} \mathrm{Th}$ values of $10^{-10}$ to $10^{-9} \mathrm{sec}^{-1}$. As we expect $w_{234} \mathrm{Th} \approx w_{232} \mathrm{Th} \ll$ $w_{238 \mathrm{U}}$ (see section 3.1), it follows that, compared to recoil, weathering is a minor source for ${ }^{234} \mathrm{Th}$ in solution. The weathering term therefore can be neglected in equation (8), so that the ${ }^{234} \mathrm{Th}$ activity in the water is directly proportional to the ratio $\varepsilon^{234} \mathrm{Th} /\left(1+\chi^{234} \mathrm{Th}\right)$.

\section{$3.3{ }^{234} U$ and $U$ isotope compositions}

The equation for the activity of dissolved ${ }^{234} \mathrm{U}$ is given in equation (9), and using $w_{234} \mathrm{Th} / \lambda_{234} \mathrm{Th} \ll \varepsilon^{234} \mathrm{Th}$ (see section 3.2 ), becomes

$$
\begin{aligned}
{ }^{234} \mathrm{U} A_{w}= & \left(\frac{\rho_{r} \cdot(1-n)}{\rho_{w} \cdot n}\right) \frac{\left(w_{234} \mathrm{U}+\varepsilon_{234} \mathrm{Th} \lambda_{234} \mathrm{U}\right)^{238 \mathrm{U}} A_{r}}{v} x \\
& +{ }^{234} \mathrm{U} A_{w 0}
\end{aligned}
$$

The activity ${ }^{234} \mathrm{U} A_{w}$ increases linearly with distance, like ${ }^{238}{ }^{2} A_{w}$ (figure 2 curve 1 ). However, unlike ${ }^{238} \mathrm{U}$, the ${ }^{234} \mathrm{U}$ activity depends not only upon the weathering rate but also upon the amount of ${ }^{234} \mathrm{Th}$ produced in the solid by $\alpha$-decay and ejected into solution by recoil. Note that the ${ }^{234} \mathrm{U}$ concentration does not depend on the extent to which ${ }^{234} \mathrm{Th}$ is associated with the surface layer; since in the present discussion $U$ is assumed not to be surface reactive, the ${ }^{238} \mathrm{U}$ in the groundwater represents the total $\mathrm{U}$ produced by decay of ${ }^{234} \mathrm{Th}$ both in the surface layer and in the solution. Therefore, the amount of ${ }^{234} \mathrm{U}$ produced by decay only depends on the abundance of total ${ }^{234} \mathrm{Th}$ ejected out of the aquifer solid.
The ${ }^{234} \mathrm{U} /{ }^{238} \mathrm{U}$ isotopic ratio, expressed as $\delta^{234} U$ (the permil deviation from secular equilibrium), is:

$$
\begin{aligned}
& \delta^{234} \mathrm{U} \\
& =\left[\frac{\frac{\rho_{r}(1-n)}{\rho_{w} n}\left(\lambda_{234} \mathrm{U} \varepsilon^{234} \mathrm{Th}\right) \frac{{ }^{238_{\mathrm{U}}} A_{r}}{{ }^{238_{\mathrm{U}}} A_{w 0}} \cdot \frac{x}{v}+\delta^{234} \mathrm{U}_{0} \cdot 10^{-3}}{\left(\frac{\rho_{r}(1-n) w_{238_{\mathrm{U}}}^{\rho_{w} \cdot n} \cdot \frac{{ }^{238} \mathrm{U}}{A_{r}}}{{ }^{23 \mathrm{U}_{\mathrm{U}}} A_{w 0}}\right) \frac{x}{v}+1}\right] \cdot 10^{3}
\end{aligned}
$$

Here, the value of $\delta^{234} \mathrm{U}$ at the water table equals $\delta^{234} \mathrm{U}_{w 0}$ and we have assumed $w_{234} \mathrm{U}=w_{238} \mathrm{U}$. The variation in ${ }^{234} \mathrm{U} /{ }^{238} \mathrm{U}$ ratio with distance can be viewed as a mixing relationship between the component added at the water table and a component from weathering and recoil that is progressively added. Therefore, $\delta^{234} \mathrm{U}_{w}$ increases with distance and reaches an asymptotic value $\left(\delta^{234} \mathrm{U}_{w \infty}\right)$ at large values of $x$ (figure 3 ). The distance necessary to reach the asymptotic value depends on the relative importance of $\delta^{234} \mathrm{U}_{w 0}$, ${ }^{238} \mathrm{U} A_{w 0}, \varepsilon_{234} \mathrm{Th}$, and $w_{234} \mathrm{U}$. For example, starting with $\delta^{234} \mathrm{U}_{w 0}=40 \%{ }^{238}{ }^{23} A_{w 0}=2 \times 10^{-3} \mathrm{dpm} / \mathrm{kg}(3 \mathrm{ng} / \mathrm{kg})$, $\varepsilon_{234} \mathrm{Th}=1 \times 10^{-3}$, and $w_{234} \mathrm{U}=1 \times 10^{-15} \mathrm{sec}^{-1}$, the $\delta^{234} \mathrm{U}_{w \infty}$ value of $90 \%$ would be reached at a distance of $10 \mathrm{~km}$. Therefore, it is clear that the input at the water table can be important for long distances in the aquifer. The asymptotic value is $\delta^{234} \mathrm{U}_{w \infty}=\left(\lambda_{234} \mathrm{U}\right.$ $\left.\varepsilon_{234} \mathrm{Th} / w_{238} \mathrm{U}\right) 10^{3}$ and is directly proportional to $\varepsilon_{234} \mathrm{Th} / w_{238} \mathrm{U}$. To generate larger isotopic shifts, either the fraction of ${ }^{234} \mathrm{Th}$ ejected by $\alpha$-recoil must be increased or the weathering rate of ${ }^{238} \mathrm{U}$ must be decreased. For a recoiled fraction $\varepsilon_{234} \mathrm{Th}=1 \times 10^{-2}$ (corresponding to a U-bearing mineral grain size of $10 \mu \mathrm{m})$, and $w_{234} \approx 1^{-15} \mathrm{sec}^{-1}$, a $\delta^{234} \mathrm{U}_{w}$ value of

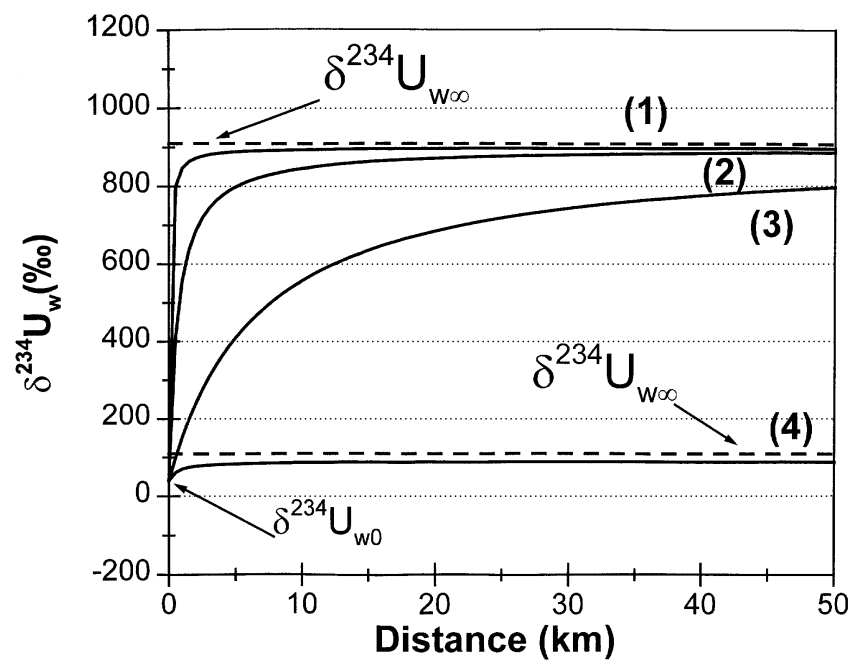

Figure 3. Isotopic evolutions of $\delta^{234} \mathrm{U}$ (in permil deviation from secular equilibrium) in the water versus distance. Evolution for a $\delta^{234} \mathrm{U}_{w \infty}$ value of $1000 \%$ o (1) low water velocity and typical recoil and weathering values; (2) typical flow velocity, recoil and weathering values; (3) typical flow velocity, low weathering rate and low recoiled fraction. Evolution for $\delta^{234} \mathrm{U}_{w \infty}$ of $90 \%$; (4) typical flow velocity, recoil and weathering values. 
$1000 \%$ would be generated, while for $\varepsilon_{234} \mathrm{Th} \approx 10^{-3}$, $\delta^{234} \mathrm{U}_{w} \approx 100 \%$. Very large values of $\delta^{234} \mathrm{U}$ associated with high U activities (see Osmond and Cowart 1992) either reflect a combination of both high $U$ activities and high isotopic shifts in waters from the vadose zone, or require very low weathering rates with very long transit distances within the saturated zone. Note that water with low water velocities will more rapidly reach the limiting value of $\delta^{234} \mathrm{U}_{w}$ (see figure 3 , curve 1).

\subsection{Other Radionuclides}

Unlike all the nuclides described above, ${ }^{228} \mathrm{Ra}$ is the first nuclide in the ${ }^{238} \mathrm{U}$ and ${ }^{232} \mathrm{Th}$ decay series that is surface reactive and has a surface-reactive parent. This can be used as an example for most of the remaining nuclides in the chain. The activity of ${ }^{228} \mathrm{Ra}$ in groundwater along a flowline (see Appendix I and figure 4) is

$$
\begin{aligned}
& { }^{228} \mathrm{Ra} A_{w}={ }^{228} \mathrm{Ra} A_{w 0} \cdot e^{-x / \bar{x}_{228} \mathrm{Ra}}
\end{aligned}
$$

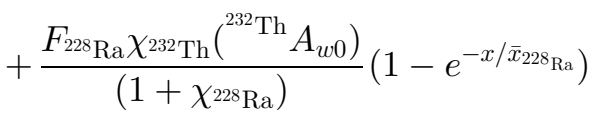

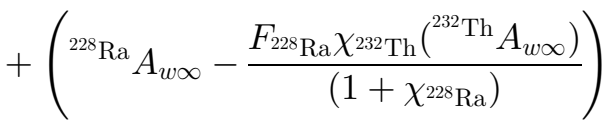

$$
\begin{aligned}
& \times\left(1-e^{-x / \bar{x}_{228_{\mathrm{Ra}}}}\right)
\end{aligned}
$$

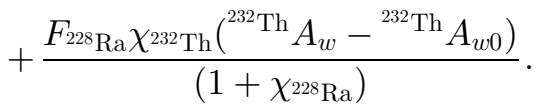

The first term in equation (11a) represents the removal from solution of ${ }^{228} \mathrm{Ra}$ supplied at the water table from the interaction with the vadose zone. The second term represents the approach to a balance between ${ }^{228} \mathrm{Ra}$ removal by decay and input from the ${ }^{232} \mathrm{Th}$ supplied at the water table. The third term describes the approach to the balance between ${ }^{228} \mathrm{Ra}$ removal by decay and inputs by weathering and recoil of ${ }^{228} \mathrm{Ra}$ from the aquifer grains. The last term is the production of ${ }^{228} \mathrm{Ra}$ in groundwater by decay of the ${ }^{232} \mathrm{Th}$ adsorbed on the surface layer that have been added along the flowline by weathering. For the activity of ${ }^{228} \mathrm{Ra}$ beyond the scale of a few kilometers (where $x \gg \bar{x}_{228}$ Ra, see table 2), equation (11a) becomes (with $\left.1+\chi_{228 \mathrm{Ra}}^{2} \approx \chi_{228 \mathrm{Ra}}\right):$

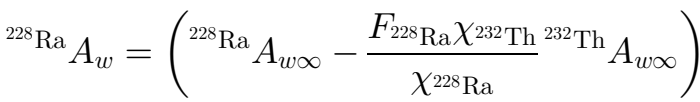

$$
\begin{aligned}
& +\frac{F_{228} \mathrm{Ra}}{\chi_{228} \chi^{232} \mathrm{Ta}}{ }^{232} \mathrm{Th} A_{w} \\
& ={ }^{228} \mathrm{Ra} A_{w I}+\frac{F_{228} \mathrm{Ra} \chi^{232} \mathrm{Th}}{\chi^{228} \mathrm{Ra}}{ }^{232} \mathrm{Th} A_{w} .
\end{aligned}
$$

Substituting for ${ }^{228} \mathrm{Ra} A_{w \infty}$ and ${ }^{232} \mathrm{Th} A_{w \infty}$, then

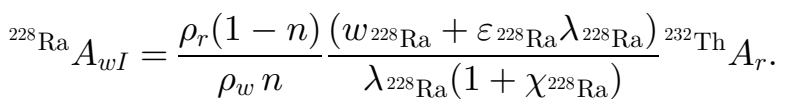

(a)

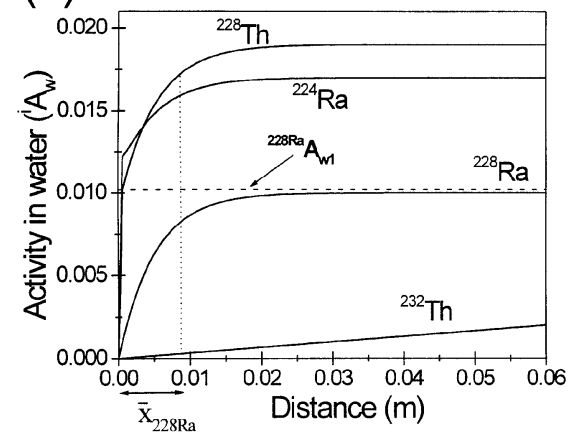

short distances

$0-0.06 \mathrm{~km}$

(b)

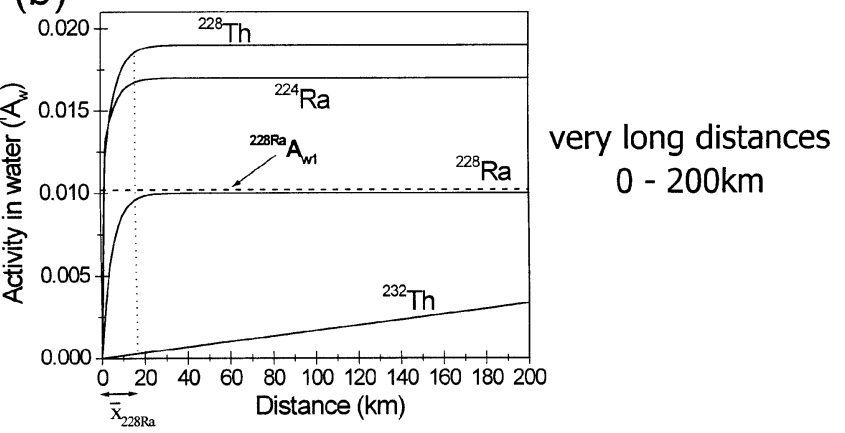

Figure 4. Activities in solution ${ }^{232}$ Th decay series nuclides as a function of distance. The three graphs represent the evolutions at several scales. ${ }^{228} \mathrm{Th} A_{w}$ and ${ }^{224} \mathrm{Ra} A_{w}$ reach very rapidly a constant activity for $x \gg \bar{x}_{228} \mathrm{Ra}$ (graph a); ${ }^{232} \mathrm{Th} A_{w}$ evolves linearly with distance (graph $\mathbf{b}) ;{ }^{228} \mathrm{Ra} A_{w}$ reaches rapidly an intermediate activity ${ }^{228} \mathrm{Ra} A_{w 1}$ and then grows linearly (graph b) over long distances.

${ }^{228} \mathrm{Ra} A_{w I}$ represents the balance between input from the aquifer mineral grains and removal of ${ }^{228} \mathrm{Ra}$ in solution. After ${ }^{228} \mathrm{Ra} A_{w I}$ is reached, the ${ }^{228} \mathrm{Ra}$ activity follows a very slowly changing value and its increase with distance is proportional to the slow increase of adsorbed ${ }^{232} \mathrm{Th}$ represented by the term $\left(\chi^{232} \mathrm{Th}\right.$ $\left.{ }^{232} \mathrm{Th} A_{w}\right)$. As discussed previously, however, ${ }^{232} \mathrm{Th}$ never reaches its asymptotic value ${ }^{232} \mathrm{Th} A_{w \infty}$ on the scale of an aquifer (section 3.1). Consequently, the ${ }^{228} \mathrm{Ra}$ activity also will not reach its limiting activity ${ }^{228} \mathrm{Ra} A_{w \infty}$ (figure 4). Note in equation (11b), where $x \gg \bar{x}_{228} \mathrm{Ra}$, the linear relationship between ${ }^{228} \mathrm{Ra}$ and ${ }^{232} \mathrm{Th}$ activities can be used to obtain a value for the ratio $\chi^{232} \mathrm{Th} / \chi^{228} \mathrm{Ra}$.

The solutions to the differential equations for the other radionuclide concentrations are presented in Appendixes I and II. As described for ${ }^{228} \mathrm{Ra}$, the activity of each nuclide along the flowline generally is dependent upon the distribution of all precursor nuclides within the decay series, so that the governing equations become progressively more complicated. However, the equations exhibit a common form of

$$
{ }^{i} A_{w}={ }^{i} A_{w 0} e^{-x / \bar{x}_{i}}+{ }^{i} A_{w \infty}\left(1-e^{-x / \bar{x}_{i}}\right)+{ }^{i} J(x)
$$

where the first term describes the evolution of the activity of $i$ supplied at the water table. The function 
${ }^{i} J(x)$ represents the component of the activity (the "transitional activity") of nuclide $i$ that evolves with distance, produced by the "transitional" decay of the precursors. The constant value of ${ }^{i} A_{w \infty}$ is reached when $\lim \left({ }^{i} J\right)_{x \rightarrow \infty}=0$ and $x \gg \bar{x}_{i}$; then the decay rate of nuclide $i$ in both the solution and the surface layer equals the net inputs into solution and the surface layer. The evolution to this constant value is described by ${ }^{i} J(x)$ :

$$
{ }^{i} J(x)=\sum_{k}^{i} \Omega_{k} \lambda_{i}\left({ }^{k} A_{w \infty}-{ }^{k} A_{w 0}\right)\left(e^{-x / \bar{x}_{k}}-e^{-x / \bar{x}_{i}}\right) .
$$

The distance required to reach the condition when ${ }^{i} J(x)$ is negligible, depends upon the relative importance of these terms, which is controlled by the values of ${ }^{i} \Omega_{k}$, the groundwater activities at infinite distance ${ }^{k} A_{w \infty}$, and the length scales $\bar{x}_{k}$ (see Appendices I and II). Note that for the daughters of ${ }^{238} \mathrm{U}$, the term ${ }^{i} \Omega_{238} \mathrm{U}=0$, since $\mathrm{U}$ is assumed not to adsorb onto the surface layer, so that $U$ does not contribute to their activities. Numerical values of $\bar{x}_{i}$, calculated with $\chi_{i}$ values typical for a sandy aquifer, are listed in table 2 and will be used for discussion.

\subsubsection{Evolution types}

The evolution of each radionuclide activity along a flowline fall into three general patterns: (1) long-lived nuclides that evolve linearly with distance over the length of the aquifer (see curve 1, figure 2); (2) shortlived nuclides that reach a constant value ${ }^{i} A_{w \infty}$ within a short distance (see curve 2); and (3) nuclides that have more complex evolutionary patterns evolving toward a constant value that is achieved only over considerable distances (curve 3).

The first case applies to ${ }^{238} \mathrm{U},{ }^{234} \mathrm{U}$ and ${ }^{232} \mathrm{Th}$, since $\bar{x}_{238} \mathrm{U}, \bar{x}_{234} \mathrm{U}$, and $\bar{x}_{232} \mathrm{Th}$ are very large (see table 2 ), and where the transport equation solutions are of the form ${ }^{i} A_{w}={ }^{i} A_{w \infty} \cdot x / \bar{x}_{i}+{ }^{i} A_{w 0}$ (see section 3.1 above). Note that ${ }^{i} A_{w \infty} / \bar{x}_{i}$ (the slope of the evolution curve) is independent of the sorption characteristics $\left(\chi_{i}\right)$ of the nuclide. The second case, where the activity reaches its limiting value very rapidly along the flow line, is illustrated by short-lived ${ }^{234} \mathrm{Th}$ (see section 3.1 ). The third case is applicable to the remaining nuclides of both decay series and is illustrated in section 3.4 by the example of ${ }^{228} \mathrm{Ra}$. For the ${ }^{232} \mathrm{Th}$ daughter nuclides ${ }^{228} \mathrm{Ra},{ }^{228} \mathrm{Th}$ and ${ }^{224} \mathrm{Ra}$, the $\bar{x}_{i}$ values are less than $3 \mathrm{~m}$ (figure 4 and table 2). Consequently, the activities of ${ }^{228} \mathrm{Ra},{ }^{228} \mathrm{Th}$ and ${ }^{224} \mathrm{Ra}$ first grow rapidly, and then follow a linear evolution following that of the ${ }^{232} \mathrm{Th}$ activity in the surface layer as the contribution from the decay of ${ }^{232} \mathrm{Th}$ in the surface layer increases. However, the activity of ${ }^{232} \mathrm{Th}$ within the surface layer is typically small over aquifers of moderate size, and so has a minor effect upon the activities of ${ }^{228} \mathrm{Ra},{ }^{228} \mathrm{Th}$ and ${ }^{224} \mathrm{Ra}$. Therefore, the activities of the ${ }^{232} \mathrm{Th}$ series daughters reach a quasi-constant value after a few meters (figure 4).

Regarding the nuclides in the ${ }^{238} \mathrm{U}$ decay series, ${ }^{234} \mathrm{U}$ is not surface reactive and so is not present in the surface layer. Also, the contribution to the daughter nuclide ${ }^{230} \mathrm{Th}$ from its parent ${ }^{234} \mathrm{U}$ in solution is minor compared to the contributions from weathering or recoil from the rock and the surface layer. Therefore, the only input of daughter ${ }^{230} \mathrm{Th}$ occurs from decay of ${ }^{234} \mathrm{U}$ in the rock and the concentration of ${ }^{230} \mathrm{Th}$ is not affected by the evolution of the parent nuclides in the decay series. Consequently, the ${ }^{230} \mathrm{Th}$ activity reaches ${ }^{230 \mathrm{Th}} A_{w \infty}$ after a distance controlled by $\bar{x}_{230} \mathrm{Th}$, while the ${ }^{226} \mathrm{Ra}$ activity reaches its limiting value after a distance controlled by $\bar{x}_{226} \mathrm{Ra}$ (since $\bar{x}_{226} \mathrm{Ra}>\bar{x}_{230} \mathrm{Th}$ ) (see table 2). The very short-lived nuclide ${ }^{222} \mathrm{Rn}$ is produced mainly by decay of ${ }^{226} \mathrm{Ra}$ in the rock and the surface layer; consequently, the value of ${ }^{222} \mathrm{Rn} A_{w}$ approaches ${ }^{222} \mathrm{Rn} A_{w \infty}$ (at a distance controlled by a characteristic of parent ${ }^{226} \mathrm{Ra}, \bar{x}^{226} \mathrm{Ra}$ (and not $\bar{x}_{222} \mathrm{Rn}$ ).

\subsection{Initial inputs from the vadose zone and at aquifer discontinuities}

The composition of groundwater at the water table $(x=0)$ generally is the result of interactions between meteoric water and the vadose zone. The solute concentrations of these waters can be low, e.g. where the volume of the unsaturated zone is minimal, or significant, e.g. where weathering rates are high over a significant soil thickness. Note that transport through the vadose zone can be modeled with a mathematical treatment similar to that developed here by incorporating the appropriate unsaturated water flow parameters. The distances over which the radionuclides in recharging groundwater are important is determined by the values of $\bar{x}_{i}$ (see table 2 ). The effect of the recharging groundwater activities on groundwater evolution is represented by the first term of the equation for ${ }^{i} A_{w}(x)$ of ${ }^{i} A_{w 0} \exp \left(-x / \bar{x}_{i}\right)$ (see equation (14)), where ${ }^{i} A_{w 0}$ is the initial input at $x=0$. The influence of water table activities disappears for $x \gg \bar{x}_{i}$. For nuclides such as ${ }^{234} \mathrm{Th},{ }^{230} \mathrm{Th},{ }^{222} \mathrm{Rn},{ }^{224} \mathrm{Ra}$, and ${ }^{228} \mathrm{Th}$, the vadose zone input is negligible after distances of $10 \mathrm{~m}$. Consequently, the activities of these nuclides in solution reflect the water-rock interactions taking place only within the aquifer.

For the long-lived nuclides ${ }^{238} \mathrm{U},{ }^{234} \mathrm{U}$ and ${ }^{232} \mathrm{Th}, \bar{x}_{i}$ is very large so that the term ${ }^{i} A_{w 0}$ can contribute significantly or dominates the groundwater activity over substantial distances. The importance of this term for radionuclide activities downgradient of groundwater flow depends upon the relative magnitudes of the subsequent inputs into solution from weathering and recoil (for ${ }^{234} \mathrm{U}$ ). In the case where the integrated input throughout the aquifer is substantially lower than the initial activity, the value of ${ }^{i} A_{w}$ remains 
relatively constant and equal to ${ }^{i} A_{w 0}$. In this case, the activities of these nuclides in solution within the aquifer reflect the interactions in the vadose zone. If the inputs into groundwater are greater than ${ }^{i} A_{w 0}$, the initial activity will be a progressively lower fraction of the total activity ${ }^{i} A_{w}$, depending upon the magnitude of the weathering rate and/or recoil rate. Therefore, it is clear that in any aquifer study, the determination of input from the vadose zone is of great importance.

Where discontinuities in the characteristics of an aquifer occur, the continuing evolution of radionuclide groundwater concentrations can be calculated by considering each homogenous segment of the aquifer as sub-units, using the activities at the discontinuity as initial values for subsequent evolution. The groundwater flowing through each aquifer segment is subject to the same controls as discussed above for a homogenous aquifer.

\subsection{Th and Ra isotope compositions}

In this section both extreme cases of dominant weathering and dominant recoil and their consequences for Th and Ra isotopic ratios will be considered. For Th, only the ${ }^{230} \mathrm{Th}$ activity is affected by recoil as well as weathering, since ${ }^{232} \mathrm{Th}$ is solely produced by weathering of the rock. In addition, we have seen in section 3.1 that ${ }^{232} \mathrm{Th}$ cannot reach the limiting activity ${ }^{232} \mathrm{Th} A_{w \infty}$ at the scale of an aquifer, while ${ }^{230} \mathrm{Th} A_{w}$ reaches the limiting value ${ }^{230} \mathrm{Th} A_{w \infty}$ after a few meters. Therefore, for distances much longer than a few meters, ${ }^{230} \mathrm{Th} A_{w} /{ }^{232} \mathrm{Th} A_{w}=\left({ }^{230} \mathrm{Th} A_{w \infty} /{ }^{232} \mathrm{Th} A_{w \infty}\right) \bar{x}_{232} \mathrm{Th} / x$. For $\mathrm{Th},\left(\chi_{232} \mathrm{Th} / \chi^{230} \mathrm{Th}\right) \approx 1$ because the desorption kinetics are much faster than the decay rate of ${ }^{232} \mathrm{Th}$ and ${ }^{230} \mathrm{Th}$ (see equations (3) and (5)). Moreover, $\left({ }^{232} \mathrm{Th} A_{r} /{ }^{238} \mathrm{U} A_{r}\right) \approx 1$ for a typical $(\mathrm{Th} / \mathrm{U})_{w t}$ ratio of 3.8 in a crustal rock. In the case where weathering is the dominant input process for ${ }^{230} \mathrm{Th}$, the ${ }^{230} \mathrm{Th} /{ }^{232} \mathrm{Th}$ activity ratio then is equal to

$$
\frac{{ }^{230} \mathrm{Th}}{\left.{ }^{2} A_{w}\right]_{\mathrm{WEATH}}}=6 \times 10^{-6}\left(\frac{w_{230} \mathrm{Th}}{w_{232} \mathrm{Th}}\right) \frac{\bar{x}_{232} \mathrm{Th}}{x} .
$$

In the case of comparable Th weathering rates, this yields $\left({ }^{230} \mathrm{Th} A\right)_{\mathrm{WEATH}} /{ }^{232} \mathrm{Th} A_{w} \approx 6 \times 10^{-6} \bar{x}_{232} \mathrm{Th} / x$. When recoil is the dominant input process for ${ }^{230} \mathrm{Th}$ $\left(w_{230} \mathrm{Th} / \lambda_{230} \mathrm{Th} \ll \varepsilon^{230} \mathrm{Th}\right)$, the $\mathrm{Th}$ isotopic ratio is

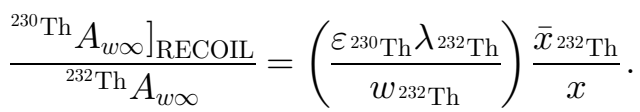

In this case, ${ }^{230} \mathrm{Th} A_{w} /{ }^{232} \mathrm{Th} A_{w}$ depends on $\varepsilon^{230} \mathrm{Th} / w_{232} \mathrm{Th}$. For values of $w_{232} \mathrm{Th}=1 \times 10^{-17} \mathrm{sec}^{-1}$ and $\varepsilon_{230} \mathrm{Th}=$ $1 \times 10^{-3}$, then $\left({ }^{230} \mathrm{Th} A\right)_{\mathrm{RECOIL}} /{ }^{232} \mathrm{Th} A \approx 2 \times 10^{-4} \bar{x}_{232} \mathrm{Th} / x$. Lower $\varepsilon^{230} \mathrm{Th} / w_{232} \mathrm{Th}$ values yield lower values for $\left({ }^{230} \mathrm{Th} A_{w}\right)_{\mathrm{RECOIL}} /{ }^{232} \mathrm{Th} A_{w}$. The condition that recoil predominates is $w_{230} \mathrm{Th} / \lambda_{230} \mathrm{Th} \ll \varepsilon^{230} \mathrm{Th}$. It follows that if $w_{230} \mathrm{Th}=w_{232} \mathrm{Th}$, then $\varepsilon_{230} \mathrm{Th} \lambda_{232} \mathrm{Th} / w_{232} \mathrm{Th} \gg \lambda_{232} \mathrm{Th} /$ $\lambda_{230} \mathrm{Th}=6 \times 10^{-6}$. Figure 5 shows the evolution with distance of the ${ }^{230} \mathrm{Th} /{ }^{232} \mathrm{Th}$ activity ratio for different

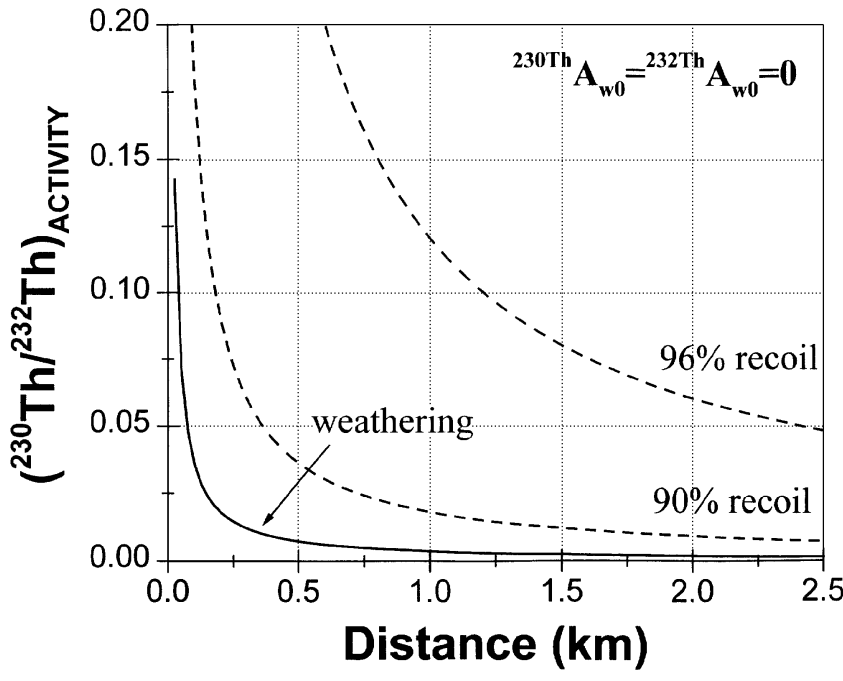

Figure 5. Evolution of ${ }^{230} \mathrm{Th} /{ }^{232} \mathrm{Th}$ activity ratios versus distance in the water for the case where weathering is the dominant input of ${ }^{230} \mathrm{Th}$ (solid line) and for the cases where input by recoil represents 90 and $96 \%$ of the ${ }^{230} \mathrm{Th}$ in water (dashed lines). Input from the water table is zero.

values of $\varepsilon_{230} \mathrm{Th} \lambda_{232} \mathrm{Th} / w_{232} \mathrm{Th}$. Since ${ }^{230} \mathrm{Th}$ reaches its limiting activity after a few meters and ${ }^{232} \mathrm{Th}$ grows linearly with distance, the ${ }^{230} \mathrm{Th} /{ }^{232} \mathrm{Th}$ activity ratio decreases with distance from an initial value determined by the input at the water table. The $\left({ }^{230} \mathrm{Th} A_{w} /\right.$ ${ }^{232} \mathrm{Th} A_{w}$ ) values for dominant recoil (greater than $90 \%$ of the ${ }^{230}$ Th produced) are at least an order of magnitude higher than in the case of dominant weathering. Knowing the concentration of ${ }^{232} \mathrm{Th}$, a value for $w_{232} \mathrm{Th}$ can be obtained and the ratio $\left.\left.{ }^{230}{ }^{\mathrm{Th}} A_{w}\right|^{232} \mathrm{Th} A_{w}\right)$ measured along a flowline (for different values of $x$ ) gives the fraction of recoiled ${ }^{230} \mathrm{Th}\left(\varepsilon_{230} \mathrm{Th}\right)$.

The ratio of ${ }^{230} \mathrm{Th}$ from recoil to that from weathering is equal to $\varepsilon^{230} \mathrm{Th} \lambda^{230} \mathrm{Th} / w_{230} \mathrm{Th}$ (Appendix II). In a sandy aquifer with $\varepsilon_{230} \mathrm{Th}=10^{-3}$ and $w_{230} \mathrm{Th}=w_{232} \mathrm{Th}=$ $10^{-17} \mathrm{sec}^{-1}$, then this ratio is equal to 30 , and the recoil process accounts for more than $96 \%$ of the ${ }^{230} \mathrm{Th}$ in solution. With $\bar{x}_{232} \mathrm{Th} \approx 600 \mathrm{~km}$, values of $\sim 2 \times 10^{-2}$ for $\left.{ }^{230} \mathrm{Th} A_{w}{ }^{232} \mathrm{Th} A_{w}\right)$ are expected after $6 \mathrm{~km}$. However, there is no data available for ${ }^{230} \mathrm{Th}$ and ${ }^{232} \mathrm{Th}$ in aquifers with low total dissolved charge, where recoil is likely to be the most important. The only examples are in the study for an aquifer dominated by carbonates by Banner et al (1990), who found activity ratios of around 8 , which is far above those calculated here for $\mathrm{Th} / \mathrm{U} \sim 4$. Further measurement of ${ }^{230} \mathrm{Th} /$ ${ }^{232} \mathrm{Th}$ in aquifers with low carbonate ratio will provide key test of the model.

For the Ra isotopic ratios, the case of predominance of weathering, as input process from the aquifer rock, requires that $w_{230} \mathrm{Th} / \lambda_{230} \mathrm{Th} \gg \varepsilon_{230} \mathrm{Th}$ (see equations in Appendices I and II) and the activity ratios become

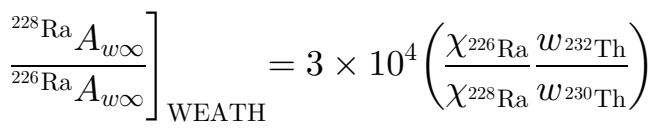


and

$$
\left.\frac{{ }^{224} \mathrm{Ra} A_{w \infty}}{{ }^{226} \mathrm{Ra} A_{w \infty}}\right]_{\text {WEATH }}=5 \times 10^{4}\left(\frac{\chi_{226} \mathrm{Ra}}{\chi^{224} \mathrm{Ra}} \frac{w_{232} \mathrm{Th}}{w^{230} \mathrm{Th}}\right) .
$$

If $w_{230} \mathrm{Th} / w_{232} \mathrm{Th}=1$, then the terms in the parentheses in equations (17) and (18), which depend on the decay constants, must be greater than unity, in which case $\left({ }^{228} \mathrm{Ra} A /{ }^{226} \mathrm{Ra} A\right)_{\mathrm{WEATH}} \approx 3 \times 10^{4}$ and $\left({ }^{224} \mathrm{Ra} \mathrm{A} /\right.$ $\left.{ }^{226} \mathrm{Ra} A\right)_{\text {WEATH }} \geq 5 \times 10^{4}$. If recoil is more significant than weathering, then

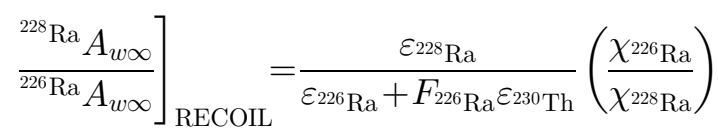

and

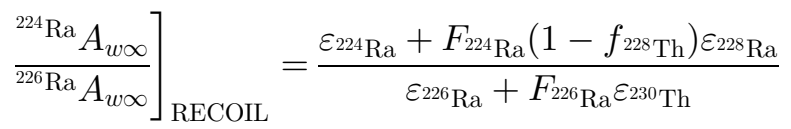

$$
\begin{aligned}
& \times\left(\frac{\chi^{226} \mathrm{Ra}}{\chi^{224} \mathrm{Ra}}\right) \text {. }
\end{aligned}
$$

With $F_{226} \mathrm{Ra}, F_{224} \mathrm{Ra}$, and $f_{228} \mathrm{Th} \approx 0.5$, and if the recoil fractions of all nuclides are comparable, then ${ }_{222}^{228} \mathrm{Ra} A$ /

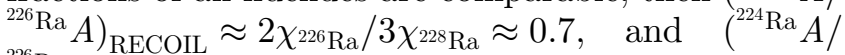
$\left.{ }^{226} \mathrm{Ra} A\right)_{\mathrm{RECOIL}} \approx \chi_{226} \mathrm{Ra} / \chi_{224 \mathrm{Ra}} \geq 1$. The $\mathrm{Ra}$ isotopic ratios then reflect the ratios of the $\chi_{\mathrm{Ra}}$ values (figure 6). Assuming that the desorption kinetics are faster than the decay rate of ${ }^{226} \mathrm{Ra}$, the mean time $\xi /{ }^{\mathrm{Ra}} \hat{k}_{-1}$ of the desorption reaction from the surface layer is much shorter than the mean life of ${ }^{226} \mathrm{Ra}\left(\xi /{ }^{\mathrm{Ra}} \hat{k}_{-1} \ll 1 /\right.$ $\lambda^{226 \mathrm{Ra}}$ ) and $\chi^{226} \mathrm{Ra} / \chi_{i}=1+\lambda_{i} \xi /{ }^{\mathrm{Ra}} \hat{k}_{-1}$ with $i={ }^{228} \mathrm{Ra}$ or ${ }^{224} \mathrm{Ra}$ (see equations 3 and 5 ). Note that $\lambda_{228} \mathrm{Ra}<\lambda_{224} \mathrm{Ra}$ gives $\chi^{226} \mathrm{Ra} / \chi^{224} \mathrm{Ra} \geq \chi^{226} \mathrm{Ra} / \chi^{228} \mathrm{Ra} ;$ and $1.5\left({ }^{228} \mathrm{Ra} \mathrm{A} /\right.$ $\left.{ }^{226} \mathrm{Ra} A\right)_{\mathrm{RECOIL}} \leq\left({ }^{224} \mathrm{Ra} A /{ }^{226} \mathrm{Ra} A\right)_{\text {RECOIL }}$ (equations (19) and (20)). The following points can be deduced: (1) the Ra activity ratios in the case when recoil is the dominant input are lower than those obtained in the case of dominant weathering. (2) Knowing $\lambda_{i}$ and $\xi$ places bounds on ${ }^{\mathrm{Ra}} \hat{k}_{-1}$ values which can be deduced from measurements of ${ }^{228} \mathrm{Ra} /{ }^{226} \mathrm{Ra}$ and ${ }^{224} \mathrm{Ra} /{ }^{226} \mathrm{Ra}$ activity ratios. As an example, assuming a thickness $\xi$ of the surface layer of $1 \mu \mathrm{m}$, and with the data for a sandy aquifer (table 2 ), a ratio $\chi_{226 \mathrm{Ra}} / \chi_{224} \mathrm{Ra}=3 \times 10^{3}$ gives ${ }^{\text {Ra }} \hat{k}_{-1} \approx 5 \times 10^{-14} \mathrm{~cm} / \mathrm{sec}$ and a mean time for the desorption reaction of $\sim 1$ year. With $\chi^{226} \mathrm{Ra}=$ $10^{3} \approx{ }^{\mathrm{Ra}} \hat{k}_{1} /{ }^{\mathrm{Ra}} \hat{k}_{-1}$, then Ra $\hat{k}_{1} \approx 2 \times 10^{-11} \mathrm{~cm} / \mathrm{sec}$ and a mean time for the adsorption reaction of $\sim 10$ hours.

Typical ${ }^{228} \mathrm{Ra} /{ }^{226} \mathrm{Ra}$ and ${ }^{224} \mathrm{Ra} /{ }^{226} \mathrm{Ra}$ activity ratios measured in groundwater vary between 0.07 and 10 (Cherdyntsev 1971; King et al 1982). The most common values are $\approx 1$ and indicate that recoil is the relevant process for $\mathrm{Ra}$ input to groundwater. However, the models developed have provided no explanation for the rather uncommon cases where observed ratios are less than unity. Note that the condition for predominance of recoil or weathering for Th and $\mathrm{Ra}$ is controlled by the same ratio $w_{230} \mathrm{Th} /$ $\left(\lambda_{230} \mathrm{Th} \varepsilon^{230} \mathrm{Th}\right)$ and so the same process must be the dominant input for both Th and Ra.

\subsection{Recoil and ${ }^{222}$ Rn activities}

The ${ }^{222} \mathrm{Rn}$ activity in water is typically orders of magnitudes higher than that of its parent, ${ }^{226} \mathrm{Ra}$ (see, for example, King et al 1982; Andrews et al 1989; Copenhaver et al 1993). Therefore, the ${ }^{226} \mathrm{Ra}$ activity in water is too low to produce the ${ }^{222} \mathrm{Rn}$ in the water. Input of ${ }^{222} \mathrm{Rn}$ by weathering from the rock is also not significant because it would require extremely high weathering rates of $10^{-8} \mathrm{sec}^{-1}$. Consequently, the dominant ${ }^{222} \mathrm{Rn}$ input into the water must be attributed to recoil from the rock and the surface layer. Due to its very short half-life (3.8 days), the ${ }^{222} \mathrm{Rn}$ activity mostly reflects local processes. The model equation for ${ }^{222} \mathrm{Rn}$ activity along the flowline depends on distance (see Appendix I). It rapidly reaches the value ${ }^{222} \mathrm{Rn} A_{w \infty}-f_{222} \mathrm{Rn} \chi^{226} \mathrm{Ra}{ }^{226} \mathrm{Ra} A_{w \infty}\left(\right.$ for $\left.x \gg \bar{x}_{230} \mathrm{Th}\right)$ and then grows to the limiting activity ${ }^{222} \mathrm{Rn} A_{w \infty}$ according to the evolution with distance of ${ }^{226} \mathrm{Ra}$ in the surface layer (figure 2). Thus, the distance required to reach a constant ${ }^{222} \mathrm{Rn}$ activity depends mainly on the value of $\bar{x}_{226} \mathrm{Ra}$. For a typical sandy aquifer, the input from ${ }^{226} \mathrm{Ra}$ in the surface layer increases along the flowline and reaches a constant value after about $1 \mathrm{~km}$.

$$
\begin{aligned}
& \text { The value of }{ }^{222} \mathrm{Rn} A_{w \infty} \text { is } \\
& { }^{222} \mathrm{Rn} A_{w \infty}=\frac{\rho_{r}(1-n)}{\rho_{w} \cdot n} \cdot\left(\varepsilon_{222} \mathrm{Rn}+f^{222} \mathrm{Rn}\right. \\
& \cdot\left(\frac{w_{226} \mathrm{Ra}}{\lambda_{226 \mathrm{Ra}}}+\varepsilon_{226 \mathrm{Ra}}+\left(1-f_{226 \mathrm{Ra}}\right)\right. \\
& \left.\left.\cdot\left(\frac{w^{230} \mathrm{Th}}{\lambda_{230} \mathrm{Th}}+\varepsilon_{230} \mathrm{Th}\right)\right)\right) \cdot{ }^{238} \mathrm{U} A_{r}
\end{aligned}
$$

and depends on the recoiled fraction of ${ }^{222} \mathrm{Rn}\left(\varepsilon_{222} \mathrm{Rn}\right)$, as well as the weathering rates and recoiled fractions of both ${ }^{226} \mathrm{Ra}$ and ${ }^{230} \mathrm{Th}\left(w_{i}\right.$ and $\varepsilon_{i}$ ) (Appendix II). The presence of $w_{230} \mathrm{Th}$ and $\varepsilon_{230} \mathrm{Th}$ represent the ${ }^{226} \mathrm{Ra}$ that contributes to ${ }^{222} \mathrm{Rn}$ in water, and was produced by ${ }^{230} \mathrm{Th}$ decay in the surface layer.

The emanation fraction is the amount of ${ }^{222} \mathrm{Rn}$ in the water of a volume of the aquifer divided by the amount of ${ }^{222} \mathrm{Rn}$ produced in the rock within the same volume. It is therefore equal to $R_{\mathrm{eman}}=\rho_{w} n^{222} \mathrm{Rn} A_{w} /$ $\rho_{r}(1-n)^{222} \mathrm{Rn} A_{r}$. Note that $R_{\text {eman }}$ depends on the porosity of the aquifer rock. For a given $R_{\text {eman }}$ value, the lower the porosity, the higher the ${ }^{222} \mathrm{Rn}$ activity in the water $\left({ }^{222} \mathrm{Rn} A_{w}\right)$. Therefore, for low porosity aquifers, a high ${ }^{222} \mathrm{Rn} A_{w}$ value can be reached and still correspond to relatively low emanation fractions. The key issue is the measurement of high ${ }^{222} \mathrm{Rn}$ emanation fractions in groundwater. The model equation for ${ }^{222} \mathrm{Rn} A_{w \infty}$, with $w_{226} \mathrm{Ra}=10^{-15} \mathrm{sec}^{-1}, w_{230} \mathrm{Th} \approx 10^{-17} \mathrm{sec}^{-1}$ and $f_{222 \mathrm{Rn}}=f_{226 \mathrm{Ra}} \approx 0.5$ and $\varepsilon_{222 \mathrm{Rn}} \approx \varepsilon_{226 \mathrm{Ra}} \approx \varepsilon_{230} \mathrm{Th}$, shows that $R_{\text {eman }} \approx 2 \varepsilon^{226} \mathrm{Ra}$. The model shows the 
following: (1) it is justified to use measured ${ }^{222} \mathrm{Rn}$ activities in water as a first order approximation of the $\varepsilon_{i}$ values for the decay series nuclides. This confirms the approach used earlier by Krishnaswami et al (1982). (2) By this model, high ${ }^{222} \mathrm{Rn}$ levels in solution could be explained by very small grain sizes. Yet $\varepsilon_{i}$ values up to $10^{-1}$ imply grain sizes smaller than $1 \mu \mathrm{m}$, and this is difficult to understand in terms of typical grain sizes of the radioactive minerals. It has been argued that efficient release of ${ }^{222} \mathrm{Rn}$ can occur within the mineral grain from a distance greater than the recoil length due to diffusion through nanopores (Rama and Moore 1984; 1990). However, laboratory experiments failed to find evidence for such mechanisms (Krishnaswami and Seidemann 1988) and further work is required to determine whether there are conditions under which such a process occurs.

Therefore, we conclude that the model of ${ }^{222} \mathrm{Rn}$ production from a surface layer in steady state does not provide an explanation for measured high ${ }^{222} \mathrm{Rn}$ emanations in pore fluids (equal to $10-20 \%$ of the rock activity). This has been a long-standing problem and recognized by many authors (e.g. Fleischer 1982; Krishnaswami and Seideman 1988; Rama and Moore 1990). One possible mechanism for explaining such high values is by attaining higher recoil fluxes from ${ }^{226} \mathrm{Ra}$ in the surface layer. In the present treatment the abundance of ${ }^{226} \mathrm{Ra}$ in the surface layer is limited by the assumption that it is in steady state and in equilibrium with the ${ }^{226} \mathrm{Ra}$ in groundwater. However, higher ${ }^{226} \mathrm{Ra}$ abundances in the surface layer, and so higher fluxes of ${ }^{222} \mathrm{Rn}$ from the layer, would result from processes that allow continuous deposition of ${ }^{226} \mathrm{Ra}$; e.g., if $\mathrm{Ra}$ is trapped in precipitated phases and does not remain in equilibrium with the water, or if barite saturation is reached. The nonsteady state will be treated elsewhere. Note also that localized zones of high weathering rates (e.g. carbonates) may be an additional source of ${ }^{222} \mathrm{Rn}$; such a mechanism may be discernible through correlations with other elements. However, at present the Rn problem remains unresolved.

\section{Conclusions}

The model developed here describes the evolution along a flowline of the activities of the ${ }^{238} \mathrm{U}$ and ${ }^{232} \mathrm{Th}$ decay series nuclides in groundwater. The processes considered here are weathering, decay, recoil by decay, and sorption. The results show that the activities reach a constant value after a distance $\bar{x}_{i}=v /$ $\lambda_{i}\left(1+\chi_{i}\right)$, characteristic of each nuclide. When $\bar{x}_{i}$ is much longer than the aquifer length (for ${ }^{238} \mathrm{U},{ }^{234} \mathrm{U}$, and ${ }^{232} \mathrm{Th}$ ), the activities grow linearly with distance. In this case the vadose zone input may predominate throughout the aquifer. When $\bar{x}_{i}$ is short compared to the aquifer length (for ${ }^{234} \mathrm{Th},{ }^{230} \mathrm{Th},{ }^{228} \mathrm{Th},{ }^{228} \mathrm{Ra}$, and
${ }^{224} \mathrm{Ra}$ ), the activities rapidly reach a constant or quasiconstant activity value. For ${ }^{226} \mathrm{Ra}$ and ${ }^{222} \mathrm{Rn}$, a limiting activity is reached after $1 \mathrm{~km}$. The vadose contributions for these nuclei are then overwhelmed by the aquifer contribution. At long distances, all activity values depend mainly on four groups of parameters: the decay constants $\left(\lambda_{i}\right)$ and the weathering rates $\left(w_{i}\right)$, the recoil fractions $\left(\varepsilon_{i}\right)$, and the distribution of the nuclides between the surface layer and the water $\left(\chi_{i}\right)$.

The isotopic ratios have been found to obey the following rules. The asymptotic value of $\delta^{234} \mathrm{U}_{w \infty}$ is $\left(\lambda_{234} \mathrm{U}^{\varepsilon_{234}} \mathrm{Th} / w_{238} \mathrm{U}\right) 10^{3}$. High values of $\delta^{234} \mathrm{U}$ will thus be provided by low weathering rates or high $\varepsilon_{234} \mathrm{Th}$. The activity ratios ${ }^{230} \mathrm{Th} /{ }^{232} \mathrm{Th},{ }^{228} \mathrm{Ra} /{ }^{226} \mathrm{Ra}$ and ${ }^{224} \mathrm{Ra} /$ ${ }^{226} \mathrm{Ra}$ have different behavior dependent on whether weathering or recoil is the predominant input mechanism. Typical values of weathering rate and recoiled fraction for a sandy aquifer indicate that recoil is the dominant input process for Th isotopes in the water. Measured data for the $\mathrm{Ra}$ isotopes activity ratios indicate that recoil is the process generally controlling the $\mathrm{Ra}$ isotopic composition in water. Higher isotopic ratios can be explained by different desorption kinetics of Ra.

From the model, the highest ${ }^{222} \mathrm{Rn}$ emanation equals $2 \varepsilon$. This is in agreement with the hypothesis that ${ }^{222} \mathrm{Rn}$ activity can be used as a first approximation for input by recoil (Krishnaswami et al 1982). However, high ${ }^{222} \mathrm{Rn}$ emanation implies unlikely small grain sizes of less than $1 \mu \mathrm{m}$, and cannot be explained by production from the surface layer as formulated in the model. The condition of equilibrium between a surface layer and the water (steady state hypothesis) fails to provide an effective means of enhancing ${ }^{222} \mathrm{Rn}$ activities. Clarification of this matter may involve study of models in which the surface layer is not in steady-state but has a continuous enhancement in precipitated material and radionuclide abundances, or models that include local rapid weathering in parts of the aquifer with very soluble phases.

The activities of the radionuclides at the water table, originating from interaction in the vadose zone, are significant. The continuing influence of these activities along the flowline depends on the nuclide half-life and on its sorption properties. For long-lived ${ }^{238} \mathrm{U},{ }^{234} \mathrm{U}$ and ${ }^{232} \mathrm{Th}$, the term ${ }^{i} A_{w 0}$ can represent a significant fraction of the activity in solution over large distances. For ${ }^{234} \mathrm{Th},{ }^{230} \mathrm{Th},{ }^{222} \mathrm{Rn},{ }^{224} \mathrm{Ra}$, and ${ }^{228} \mathrm{Th}$, the vadose zone input has a negligible effect after distances of $10 \mathrm{~m}$.

The model can be applied to natural aquifers to obtain $\bar{x}_{i}$ and $\chi_{i}$ values from measured radionuclide activities, and to obtain information on retardation factors and on the kinetics of sorption processes. Inversely, nuclide activities in groundwater can be predicted from the model, using distribution coefficients determined in laboratory experiments. Future 
refinement to the model will involve considering the cases where the water and the surface layer are not in steady state, in particular the case where precipitation onto the surface layer occurs.

\section{Appendix I}

Radionuclide groundwater concentrations as a function of distance are obtained by sequentially solving equations 1 and 2 for nuclides along the ${ }^{238} \mathrm{U}$ and ${ }^{232} \mathrm{Th}$ decay series. (See Appendix II for the expressions of $\left.{ }^{i} A_{w \infty}\right)$.

\section{${ }^{238}$ U-Series}

- ${ }^{238} \mathrm{U} A_{w}={ }^{238} \mathrm{U} A_{w 0} e^{-x / \bar{x}_{238} \mathrm{U}}+{ }^{238} \mathrm{U} A_{w \infty}\left(1-e^{-x / \bar{x}_{238} \mathrm{U}}\right)$,

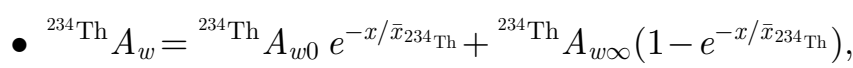

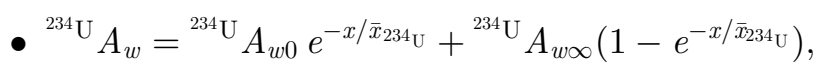

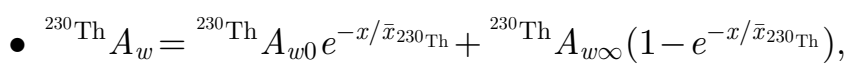

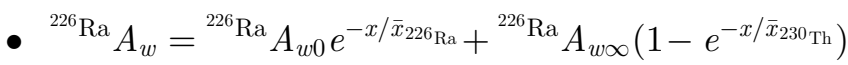

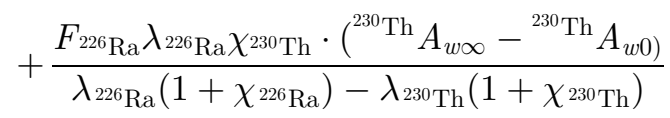

$\cdot\left(e^{-x / \bar{x}_{230} \mathrm{Th}}-e^{-x / \bar{x}_{226 \mathrm{Ra}}}\right)$,

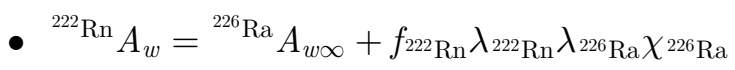

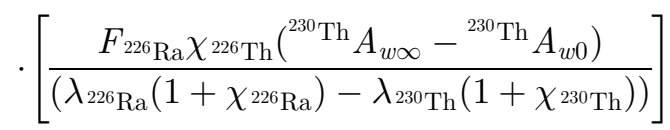

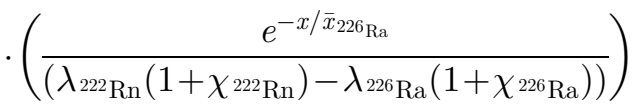

$-f_{222} \mathrm{Rn} \lambda_{222} \mathrm{Rn} \lambda^{226} \mathrm{Ra} \chi \chi^{226} \mathrm{Ra}$

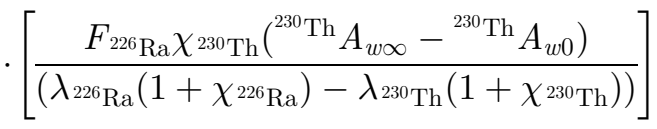

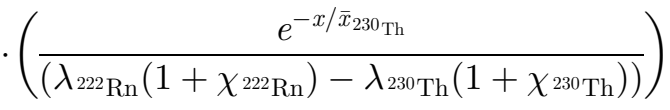

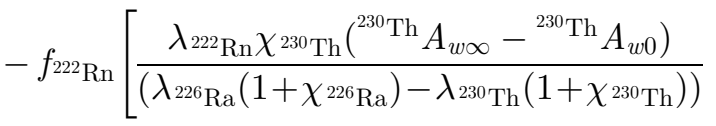

$\left.\cdot\left(1-2 f_{226} \mathrm{Ra}\right) \cdot\left(\frac{\lambda_{226} \mathrm{Ra} \xi}{R a \hat{k}_{-1}+\lambda_{226 \mathrm{Ra}} \xi}\right)\right] \cdot e^{-x / \bar{x}_{230} \mathrm{Th}}$

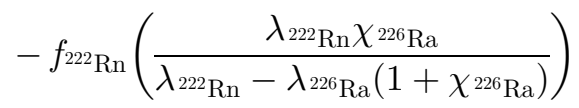

. $\left({ }^{226} \mathrm{Ra} A_{w \infty}-{ }^{226} \mathrm{Ra} A_{w 0}\right) e^{-x / \bar{x}_{226} \mathrm{Ra}}$.
Note that the equation for ${ }^{222} \mathrm{Rn}$ activity can be rewritten as:

- ${ }^{222} \mathrm{Rn} A_{w}=\left[{ }^{222} \mathrm{Rn} A_{w \infty}-f_{222} \mathrm{Rn} \chi^{226} \mathrm{Rn}{ }^{226} \mathrm{Ra} A_{w \infty}\right.$

$\left.-f_{222 \mathrm{Rn}} \chi^{226 \mathrm{Ra}} F_{226} \mathrm{Ra} \frac{\lambda_{226} \mathrm{Ra}}{\lambda_{222} \mathrm{Rn}} \chi^{230}{ }^{230}{ }^{230} \mathrm{Th} A_{w \infty}\right]$

$+f^{222} \mathrm{Rn} \chi^{226}{ }^{226}{ }^{22 \mathrm{Ra}} A_{w}$

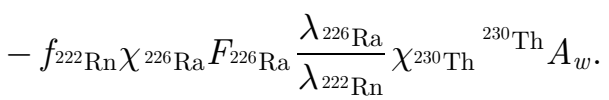

\section{${ }^{232}$ Th-Series:}

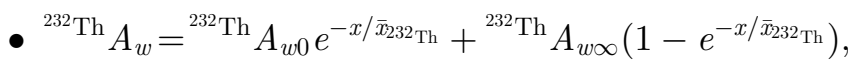

- ${ }^{228} \mathrm{Ra} A_{w}={ }^{228} \mathrm{Ra} a A_{w 0} e^{-x / \bar{x}_{228} \mathrm{Ra}}+{ }^{228} \mathrm{Ra} A_{w \infty}\left(1-e^{-x / \bar{x}_{228} \mathrm{Ra}}\right)$

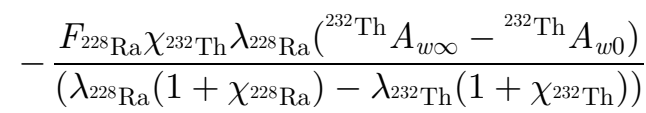

$\times\left(e^{-x / \bar{x}_{232} \mathrm{Th}}-e^{-x / \bar{x}_{228} \mathrm{Ra}}\right)$,

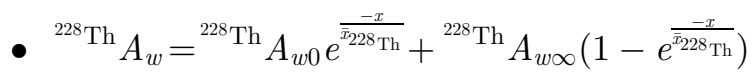

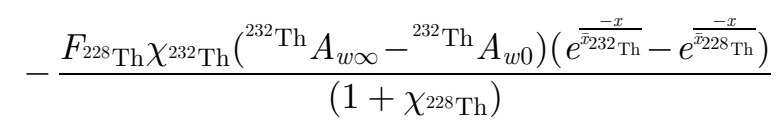

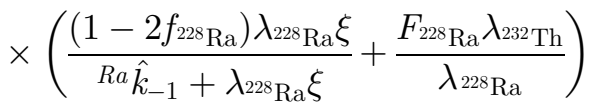

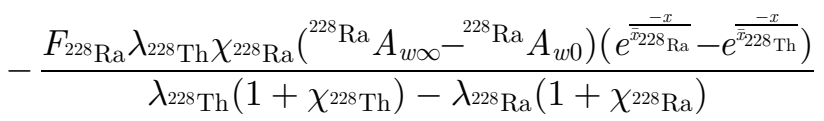

$\times\left[\frac{F_{228} \mathrm{Ra} \chi^{232} \mathrm{Th} \lambda^{232} \mathrm{Th}}{\lambda_{228} \mathrm{Ra}\left(1+\chi^{228} \mathrm{Ra}\right)}-1\right]$,

- ${ }^{224} \mathrm{Ra} A_{w}={ }^{224} \mathrm{Ra} A_{w \infty}$

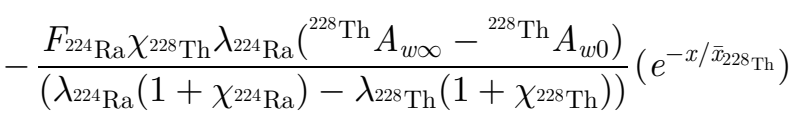

$-\frac{\chi_{228} \mathrm{Th} F_{228} \mathrm{Th} \lambda_{228} \mathrm{Th}\left(e^{-x / \bar{x}_{228} \mathrm{Ra}}\right)}{\lambda_{228 \mathrm{Th}}\left(1+\chi^{228} \mathrm{Th}\right)-\lambda_{228} \mathrm{Ra}\left(1+\chi^{228} \mathrm{Ra}\right)}$

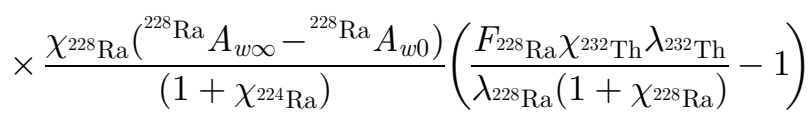

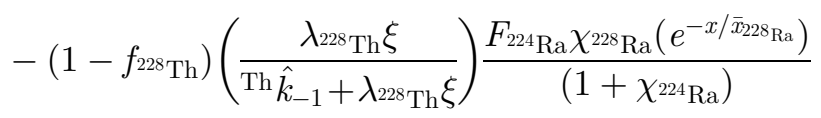

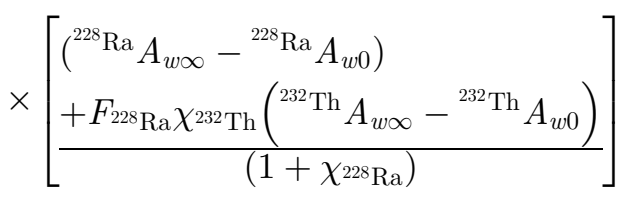

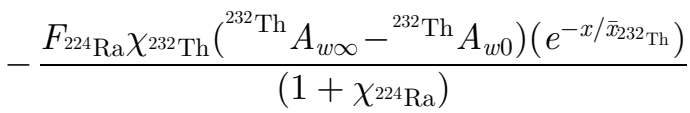




$$
\begin{aligned}
& \times\left(1-f_{228} \mathrm{Ra}\right)
\end{aligned}
$$

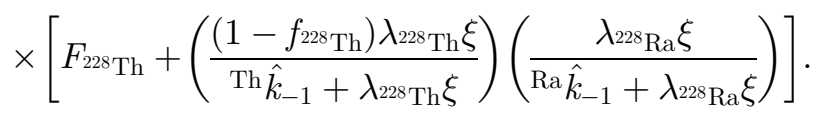

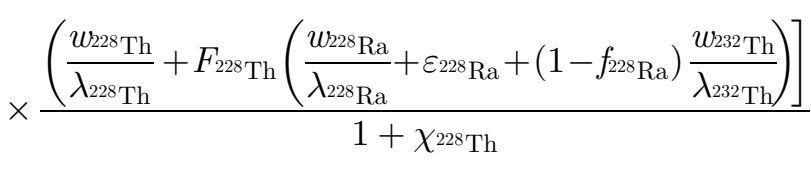

$$
\begin{aligned}
& \times{ }^{232} \mathrm{Th} A_{r},
\end{aligned}
$$

\section{Appendix II}

Equations for the activities of the ${ }^{238} \mathrm{U}$ and ${ }^{232} \mathrm{Th}$ decay series nuclides when $x \rightarrow \infty$.

\section{${ }^{238} \mathbf{U}$-Series}

$$
\begin{aligned}
& -{ }^{238} \mathrm{U} A_{w \infty}=\left(\frac{\rho_{r} \cdot(1-n)}{\rho_{w} \cdot n}\right) \frac{w_{238} \mathrm{U}}{\lambda_{238} \mathrm{U}}{ }^{238} \mathrm{U} A_{r}, \\
& \text { - } \left.{ }^{234} \mathrm{Th} A_{w \infty}=\left(\frac{\rho_{r} \cdot(1-n)}{\rho_{w} \cdot n}\right) \cdot \frac{\left(w_{234} \mathrm{Th}+\varepsilon_{234} \mathrm{Th} \cdot \lambda_{234} \mathrm{Th}\right)}{\lambda_{234} \mathrm{Th}\left(1+\chi^{234} \mathrm{Th}\right.}\right) A_{r}, \\
& -{ }^{234} \mathrm{U} A_{w \infty}=\left(\frac{\rho_{r}(1-n)}{\rho_{w} \cdot n}\right) \\
& \times \frac{\left(w_{234} \mathrm{U}+w_{234} \mathrm{Th} \frac{\lambda_{234 \mathrm{U}}}{\lambda_{234} \mathrm{Th}}+\varepsilon_{234} \mathrm{Th} \lambda^{234} \mathrm{U}\right)}{\lambda_{234} \mathrm{U}}{ }^{238} \mathrm{U} A_{r},
\end{aligned}
$$

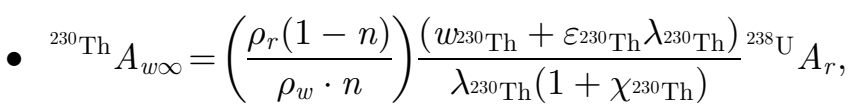

- ${ }^{226} \mathrm{Ra} A_{w \infty}=\frac{1}{1+\chi^{226} \mathrm{Ra}}$

$$
\times\left(\frac{\rho_{r} \cdot(1-n)}{\rho_{w} \cdot n}\left(\frac{w_{226} \mathrm{Ra}}{\lambda_{226} \mathrm{Ra}}+\varepsilon_{226} \mathrm{Ra}\right){ }^{230} \mathrm{Th} A_{r}\right.
$$$$
\left.+F_{226 \mathrm{Ra}} \chi^{230}{ }^{230}{ }^{230} A_{w \infty}\right),
$$

- ${ }^{222} \mathrm{Rn} A_{w \infty}=\frac{\rho_{r}(1-n)}{\rho_{w} n}\left(\varepsilon_{222 \mathrm{Rn}}+f_{222 \mathrm{Rn}}\left(\frac{w_{226} \mathrm{Ra}}{\lambda_{226} \mathrm{Ra}}\right.\right.$

$$
\left.\left.+\varepsilon_{226 \mathrm{Rn}}+\left(1-f_{226 \mathrm{Rn}}\right)\left(\frac{w_{230} \mathrm{Th}}{\lambda_{230} \mathrm{Th}}+\varepsilon^{230} \mathrm{Th}\right)\right)\right)^{238} \mathrm{U} A_{r} .
$$

\section{${ }^{232}$ Th-Series:}

$$
\begin{gathered}
-{ }^{232} \mathrm{Th} A_{w \infty}=\frac{\rho_{r}(1-n)}{\rho_{w} n}\left(\frac{w_{232} \mathrm{Th}}{\lambda_{232} \mathrm{Th}\left(1+\chi^{232} \mathrm{Th}\right)}\right){ }^{232} \mathrm{Th} A_{r}, \\
-{ }^{228} \mathrm{Ra} A_{w \infty}=\frac{\rho_{r}(1-n)}{\rho_{w} n} \\
\times \frac{\left(\frac{w_{228} \mathrm{Ra}}{\lambda_{228} \mathrm{Ra}}+\varepsilon^{228} \mathrm{Ra}+F_{228} \mathrm{Ra} \frac{w_{232} \mathrm{Th}}{\lambda_{232} \mathrm{Th}}\right)}{1+\chi^{228} \mathrm{Ra}} \cdot{ }^{{ }^{332} \mathrm{Th}} A_{r}, \\
-{ }^{228} \mathrm{Th} A_{w \infty}=\frac{\rho_{r}(1-n)}{\rho_{w} n}
\end{gathered}
$$

$$
\begin{aligned}
& \text { - }{ }^{224} \mathrm{Ra} A_{w \infty}=\frac{\rho_{r}(1-n)}{\rho_{w} n} \frac{\left(\frac{w_{224} \mathrm{Ra}}{\lambda_{224} \mathrm{Ra}}+\varepsilon^{224} \mathrm{Ra}\right)}{1+\chi^{224} \mathrm{Ra}}{ }^{228} \mathrm{Th} A_{r} \\
& +\frac{F_{224} \mathrm{Ra} \chi^{228} \mathrm{Th}}{1+\chi^{224} \mathrm{Ra}}{ }^{228} \mathrm{Th} A_{w \infty}
\end{aligned}
$$

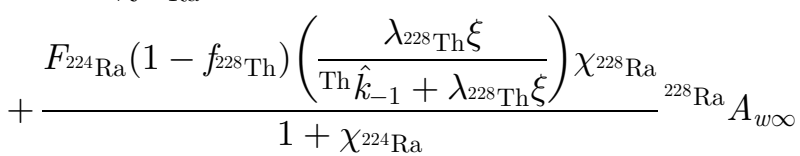

$$
\begin{aligned}
& F_{224 \mathrm{Ra}}\left(1-f_{228 \mathrm{Th}}\right)\left(\frac{\lambda_{228} \mathrm{Th}}{\operatorname{Th} \hat{k}_{-1}+\lambda_{228 \mathrm{Th}} \xi}\right) \\
& +\frac{\left(1-f_{228} \mathrm{Ra}\right)\left(\frac{\lambda_{228} \mathrm{Ra} \xi}{\mathrm{Ra} \hat{k}_{-1}+\lambda_{228} \mathrm{Ra}}\right) \chi^{232} \mathrm{Th}}{1+\chi^{224} \mathrm{Ra}}{ }^{{ }^{232} \mathrm{Th}} A_{w \infty} .
\end{aligned}
$$

\section{Acknowledgments}

This work was funded by DOE grant \#DE-FG0388ER13851, contribution \#8606(1024).

\section{References}

Allen H E, Perdue E M and Brown D S 1993 Metals in Groundwater (Lewis Publishers)

Andrews J N and Kay R L F $1982{ }^{234} \mathrm{U} /{ }^{238} \mathrm{U}$ activity ratio of dissolved uranium in groundwaters from a Jurassic limestone aquifer in England; Earth Planet. Sci. Lett. 57 139-151

Andrews J N, Ford D J, Hussain N, Trivedi D and Youngman M J 1989 Natural radioelement solution by circulating groundwaters in the Stripa granite; Geochim. Cosmochim. Acta 53 1791-1802

Banner J, Wasserburg G J, Chen J H and Moore C H 1990 ${ }^{234} \mathrm{U}_{2}{ }^{238} \mathrm{U}_{-}{ }^{230} \mathrm{Th}_{-}{ }^{232} \mathrm{Th}$ systematics in saline groundwaters from central Missouri; Earth Planet. Sci. Lett. 101 296-312

Bonotto D M and Andrews J N 1993 The mechanism of ${ }^{234} \mathrm{U} /$ ${ }^{238} \mathrm{U}$ activity ratio enhancement in karstic limestone groundwater; Chemical Geology (Isotope Geoscience Section) 103 193-206

Cherdyntsev V V 1971 Uranium-234. 234p. Israel Program for Scientific Translations, Jerusalem pp. 62-68

Coles D G and Ramspott L 1982 Migration of Ru-106 in a Nevada test-site aquifer - Discrepancy between field and laboratory results; Science 215 1235-1237

Copenhaver S A, Krishnaswami S, Turekian K, Epler N and Cochran J K 1993 Retardation of ${ }^{238} \mathrm{U}$ and ${ }^{232} \mathrm{Th}$ decay chain radionuclides in Long Island and Connecticut aquifers; Geochim. Cosmochim. Acta 57 597-603

Davidson M R and Dickson B L 1986 A porous flow model for steady state transport of radium in groundwater; Wat. Resour. Res. 22 34-44

Dozol M et al 1993 Radionuclide migration in groundwaters: review of the behaviour of actinides (Technical report); Pure and Applied Chemistry 1082-1101 
Fleischer R L 1982 Alpha-recoil damage and solution effects in minerals: uranium isotopic disequilibrium and radon release; Geochim. Cosmochim. Acta 46 2191-2201

Hodge V F, Johannesson K H and Stetzenbach K 1996 Rhenium, Molybdenum, and Uranium in groundwater from the Southern Great-Basin, USA-Evidence for conservative behavior; Geochim. Cosmochim. Acta 60 3197-3214

Hubbard N, Laul J C and Perkins R W 1984 The use of natural radionuclides to predict the behavior of radwaste radionuclides in far-field aquifers; Scientific basis for nuclear waste management $V$

Ivanovich M, Latham A G, Longworth G and Gascoyne M 1992 Uranium-series disequilibrium: application to radioactive waste disposal studies; In Uranium-series Disequilibrium (ed) Ivanovich and Harmon (Oxford Science Publications) pp. $583-630$

Kigoshi K 1971 Alpha-Recoil Thorium-234: Dissolution into water and the Uranium-234/Uranium-238 disequilibrium in nature; Science $\mathbf{1 7 3}$ 47-48

King P T, Michel J and Moore W S 1982 Ground water geochemistry of ${ }^{224} \mathrm{Ra},{ }^{226} \mathrm{Ra}$ and ${ }^{222} \mathrm{Rn}$. Geochim. Cosmochim. Acta 46 1173-1182

Krishnaswami S, Graustein W S and Turekian K K and Dowd J F 1982 Radium, thorium and radioactive lead isotopes in groundwaters: application to the in situ determination of adsorption-desorption rate constants and retardation factors; Water Resour. Res. 18(6) 1663-1675

Krishnaswami S and Seidemann D E 1988 Comparative study of ${ }^{222} \mathrm{Rn},{ }^{40} \mathrm{Ar},{ }^{39} \mathrm{Ar}$ and ${ }^{37} \mathrm{Ar}$ leakage from rocks and minerals.
Implication for the role of nanopores in gas transport through natural silicates; Geochim. Cosmochim. Acta 52 655-658

Ku T L, Luo S, Leslie B W and Hammond D E 1992 Decayseries disequilibria applied to the study of rock-water interaction and geothermal systems. In Uranium-series Disequilibrium: application to Earth, Marine, and Environmental Sciences (ed) M Ivanovich and R S Harmon (Oxford Science Publications)

Langmuir D 1997 Aqueous environmental geochemistry 600p. (Prentice Hall)

Osmond J K and Cowart J B 1992 Ground water. In Uraniumseries Disequilibrium: application to Environmental Problems (ed) M Ivanovich and R S Harmon (Oxford Science Publications) pp. 204-245

Osmond J K and Ivanovich M 1992 Uranium-series mobilization and surface hydrology; In Uranium-series Disequilibrium: application to Earth, Marine, and Environmental Sciences (ed) M Ivanovich and R S Harmon (Oxford Science Publications) pp. 290-333

Rama and Moore W S 1984 Mechanism of transport of U-Th series of radioisotopes from solids into groundwater; Geochim. Cosmochim. Acta 48 395-399

Rama and Moore W S 1990 Submicronic porosity in common minerals and emanation of radon; Nuc. Geophy. 4 467-473

Tricca A, Porcelli D, Baskaran M and Wasserburg G J (2000) The transport of U- and Th-Series nuclides in a sandy unconfined aquifer, Geochim. Cosmochim. Acta (submitted)

Zheng C and Bennett G D 1995 Applied contaminant transport modeling (Van Nostrand Reinhold) $440 \mathrm{p}$ 